\title{
Isthminia panamensis, a new fossil inioid (Mammalia, Cetacea) from the Chagres Formation of Panama and the evolution of 'river dolphins' in the Americas
}

Nicholas D Pyenson, Jorge Velez-Juarbe, Carolina S. Gutstein, Holly Little, Dioselina Vigil, Aaron O'Dea

In contrast to dominant mode of ecological transition in the evolution of marine mammals, different lineages of toothed whales (Odontoceti) have repeatedly invaded freshwater ecosystems during the Cenozoic era. The so-called 'river dolphins' are now recognized as independent lineages that converged on similar morphological specializations (e.g., longirostry). In South America, the two endemic 'river dolphin' lineages form a clade (Inioidea), with closely related fossil inioids from marine rock units in the South Pacific and North Atlantic oceans. Here we describe a new genus and species of fossil inioid, Isthminia panamensis, gen. et nov. sp., from the late Miocene of Panama. The type and only known specimen consists of a partial skull, mandibles, isolated teeth, a right scapula, and carpal elements recovered from the Piña Facies of the Chagres Formation, along the Caribbean coast of Panama. Sedimentological and associated fauna from the Piña Facies point to fully marine conditions with high planktonic productivity about 6.1-5.8 million years ago (Messinian), pre-dating the final closure of the Isthmus of Panama. Along with ecomorphological data, we propose that Isthminia was primarily a marine inhabitant, similar to modern oceanic delphinoids. Phylogenetic analysis of fossil and living inioids, including new codings for Ischyrorhynchus, an enigmatic taxon from the late Miocene of Argentina, places Isthminia as the sister taxon to Inia, in a broader clade that includes Ischyrorhynchus and Meherrinia, a North American fossil inioid. This phylogenetic hypothesis complicates the possible scenarios for the freshwater invasion of the Amazon River system by stem relatives of Inia, but it remains consistent with a broader marine ancestry for Inioidea. Based on the fossil record of this group, along with Isthminia, we propose that a marine ancestor of Inia invaded Amazonia during eustatic sea-level highs during the late Miocene. 


\section{PeerJ}

2

3 Isthminia panamensis, a new fossil inioid (Mammalia, Cetacea) from the Chagres

4 Formation of Panama and the evolution of 'river dolphins' in the Americas

5

6 Nicholas D. Pyenson*1,2, Jorge Vélez-Juarbe ${ }^{3,4}$, Carolina S. Gutstein ${ }^{1,5}$, Holly Little ${ }^{1}$, Dioselina

7 Vigil $^{6}$, and Aaron O’Dea ${ }^{6}$

8

$9{ }^{1}$ Department of Paleobiology, National Museum of Natural History, Smithsonian Institution, PO

Box 37012, Washington, DC 20013, USA

$11{ }^{2}$ Departments of Mammalogy and Paleontology, Burke Museum of Natural History and Culture,

12 Seattle, WA 98195, USA

${ }^{3}$ Department of Mammalogy, Natural History Museum of Los Angeles County, Los Angeles, CA 90007, U.S.A.

${ }^{4}$ Florida Museum of Natural History, University of Florida, Gainesville, FL 32611, U.S.A.

${ }^{5}$ Comisión Patrimonio Natural, Consejo de Monumentos Nacionales, Av. Viña del Mar,

17 Providencia, Santiago, Chile

*Author for correspondence. Email: pyensonn@si.edu 
$\underline{\text { Abstract }}$

In contrast to dominant mode of ecological transition in the evolution of marine mammals, different lineages of toothed whales (Odontoceti) have repeatedly invaded freshwater ecosystems during the Cenozoic era. The so-called 'river dolphins' are now recognized as independent lineages that converged on similar morphological specializations (e.g., longirostry). In South America, the two endemic 'river dolphin' lineages form a clade (Inioidea), with closely related fossil inioids from marine rock units in the South Pacific and North Atlantic oceans. Here we describe a new genus and species of fossil inioid, Isthminia panamensis, gen. et nov. sp., from the late Miocene of Panama. The type and only known specimen consists of a partial skull, mandibles, isolated teeth, a right scapula, and carpal elements recovered from the Piña Facies of the Chagres Formation, along the Caribbean coast of Panama. Sedimentological and associated fauna from the Piña Facies point to fully marine conditions with high planktonic productivity about 6.1-5.8 million years ago (Messinian), pre-dating the final closure of the Isthmus of Panama. Along with ecomorphological data, we propose that Isthminia was primarily a marine inhabitant, similar to modern oceanic delphinoids. Phylogenetic analysis of fossil and living inioids, including new codings for Ischyrorhynchus, an enigmatic taxon from the late Miocene of Argentina, places Isthminia as the sister taxon to Inia, in a broader clade that includes Ischyrorhynchus and Meherrinia, a North American fossil inioid. This phylogenetic hypothesis complicates the possible scenarios for the freshwater invasion of the Amazon River system by stem relatives of Inia, but it remains consistent with a broader marine ancestry for Inioidea. Based on the fossil record of this group, along with Isthminia, we propose that a marine ancestor of Inia invaded Amazonia during eustatic sea-level highs during the late Miocene. 


\section{Introduction}

In the evolution of marine mammals, the dominant mode of their ecological transitions (sensu Vermeij \& Dudley, 2000) is the iterative adaptation to marine life from terrestrial ancestry (Thewissen \& Williams, 2002; Gingerich, 2005; Kelley \& Pyenson, 2015). However, the direction of this ecological transition is not exclusively from land to sea: throughout the late Cenozoic, several lineages of cetaceans and pinnipeds have evolved exclusively freshwater lifestyles from a marine ancestry (Hamilton et al., 2001; Pyenson et al., 2014a). Among cetaceans, the group of extant 'river dolphins' are the best exemplars of this ecological mode. This non-monophyletic (i.e., paraphyletic or possibly polyphyletic) group traditionally includes four different living species: Platanista gangetica (Lebeck, 1801); Lipotes vexillifer Miller, 1918, Inia geoffrensis (Blainville, 1817), and Pontoporia blainvillei (Gervais \& d'Orbigny, 1844). These species all show broad morphological similarities, including longirostral skulls and jaws, reduced orbits, flexible necks, and broad, paddle-shaped flippers (Geisler et al., 2011).

Notably, this assemblage of broadly convergent taxa has a biogeographic distribution across different freshwater river systems of South Asia and South America, and in estuarine and coastal waters of the latter as well.

While work for most of $20^{\text {th }}$ century implied or proposed that the 'river dolphins' were all most closely related to one another (e.g., Simpson, 1945), the advent of molecular phylogenies clarified that these lineages are not all directly related to one another (see Geisler et al., 2011 for a useful summary), although both molecular and morphological analyses consistently group the two South American genera, Inia and Pontoporia, as sister taxa (Inioidea sensu Muizon, 1988a). Lipotes, which was endemic to the Yangtze River of China and is likely extinct (Turvey et al., 
2010), may be the sister taxon to Inioidea (see Geisler et al., 2011), although all molecular studies (e.g., Messenger \& McGuire, 1998; Hamilton et al., 2001; Nikaido et al., 2001; Geisler \& Sanders, 2003; Arnason et al., 2004; May-Collado \& Agnarsson, 2006; McGowen et al., 2009; Steeman et al., 2009; Geisler et al., 2011) and combined molecular and morphological analyses (Geisler et al., 2011; Gatesy et al., 2012) place Lipotes within Delphinida (i.e., Inioidea + Delphinoidea sensu Muizon 1988a), and furthermore place Platanista outside of Delphinida. Lipotes and Platanista have only been grouped together in analyses using purely morphological datasets (e.g., Geisler \& Sanders, 2003).

With restricted distributions, serious conservation threats, and relatively low taxonomic richness compared with other odontocete clades, the evolutionary history of 'river dolphins' remains a topic of perennial interest (Cassens et al., 2000; Hamilton et al., 2001; Nikaido et al., 2001; Pyenson, 2009; Ruiz-Garcia \& Shostell, 2010; Turvey et al., 2010; Geisler et al., 2011). The fossil record of South Asian 'river dolphins' is poor, with no taxa reported from undisputable remains (e.g., Prolipotes yujiangensis Zhou et al., 1984 is known only from an isolated mandible that cannot be clearly diagnosed). By contrast, fossil South American 'river dolphins' have been reported from Neogene rocks of the continent since the 1850s (Cozzuol, 1996). The majority of these fossil taxa have been assigned to the traditional taxonomic groups of either Iniidae or Pontoporiidae, based on diagnostic features of the face and vertex (Muizon, 1988a), and include taxa (e.g., Pontistes rectifrons Burmeister, 1885, Pliopontos littoralis Muizon, 1983, Brachydelphis mazeasi Muizon, 1988b) known from marine rocks units of middle Miocene through early Pliocene age in Argentina, Peru, Chile, and elsewhere (Muizon, 1984; Muizon, 1988b; Cozzuol, 1996; Gutstein et al. 2009; Lambert \& Muizon, 2013; Gutstein et al. 2014a). 
92 Recently, Bianucci et al. (2013) reported an isolated periotic with diagnostic features of

93 Platanistinae (today limited to South Asia) from the Peruvian Amazon Basin of Laventan South

94 American Land Mammal Age. This finding is striking for its disjunct biogeographic occurrence,

95 relative to living Platanista in South Asia, but it is consistent with the widespread distribution of

96 fossil platanistoids reported elsewhere in the world from late Paleogene through Neogene rocks

97 along the coasts of the South and North Pacific and the North Atlantic oceans (Fordyce, 2009).

Similarly, the fossil record of inioids extends well beyond South America (Fig. 1). Fossil

pontoporiids have been described from shallow marine and estuarine strata of early late Miocene

to early Pliocene age from the Atlantic coast of North America, including Maryland, Virginia,

North Carolina and Florida (Morgan, 1994; Whitmore, 1994; Godfrey \& Barnes, 2008; Gibson

\& Geisler, 2009; Geisler et al., 2012). Along the Atlantic coast of Europe, Protophocaena

minima Abel, 1905 from shallow marine Miocene of the Netherlands, is now recognized as a pontoporiid (Lambert \& Post, 2005) based on additional cranial and periotic material from the Miocene of Belgium and the Netherlands. Pyenson \& Hoch (2007) reported pontoporiids (cf. Pontistes sp. and indeterminate Pontoporiidae) from the marine Gram Formation in Denmark, which is early late Miocene age. To date, no fossil pontoporiids have been described from the North Pacific Ocean. The two species of Parapontoporia Barnes 1984, which are well known from abundant Mio-Pliocene localities in northern and southern California (Boessenecker \&

111 Poust, 2015), are not pontoporiids, but belong in a clade with Lipotes (Geisler et al., 2012),

112 although Parapontoporia is sometimes also grouped with Platanista, Lipotes and

113 Ischyrorhynchus vanbenedeni Ameghino, 1891 (see Aguirre-Fernández \& Fordyce, 2014).

114 Historically, fossils referred to Iniidae include a variety of taxa (e.g., Goniodelphis hudsoni 
115 Allen, 1941; Ischyrorhynchus), supplementing the existing data showing a much broader

116 geographic extent for inioids in the fossil record than today (Fig. 1). These fossil occurrences

117 thus raise the question of how Inioidea evolved, and the evolutionary scenarios that led to their

118 current distribution. Our description herein of a new genus and new species of Inioidea from the

119 late Miocene of Panama, based on substantially more osteological material than most fossil

120 inioids, provides new insight into the evolutionary scenarios under which this group evolved in

121 South America, including the timing and mode of major ecological transitions

122

\section{$123 \underline{\text { Methods }}$}

\section{Excavation at the Type Locality}

125 The type specimen of this new taxon was initially discovered in an intertidal zone outcrop of the 126 Chagres Formation, near the town of Piña, along the Caribbean coastline of Panama, in early

1272011 (Fig. 2, Supplemental Fig. S1). The infrequency of low tides at the type locality of this 128 specimen created a narrow time window for excavating the specimen, which several co-authors 129 (NDP, JVJ, DV, and AO) undertook on 18 June 2011 with the assistance of staff from 130 Smithsonian Tropical Research Institute (STRI). After exporting the specimen under permits 131 from Panama's Ministerio de Comercio e Industrias (MICI number DNRM-MC-074-11) to the 132 Smithsonian's National Museum of Natural History (NMNH) in Washington, D.C., U.S.A., the 133 specimen was prepared using mechanical tools and consolidated using standard fossil vertebrate 134 preparation techniques by DV, S. Jabo, and P. Kroehler in the Vertebrate Paleontology

135 Preparation Laboratory in the Department of Paleobiology at NMNH. 136

137 Digital Methods 
138 During excavation at the type locality (Supplemental Fig. S1), we documented in situ skeletal

139 remains using a Flip camera (Cisco Systems Inc., San Jose, California) on time-lapse settings.

140 Later, subsequent to the specimen's preparation in the Department of Paleobiology at USNM, we

141 used computed tomography (CT) to scan the type specimen USNM 546125 in the Department of

142 Anthropology with a Siemens Somatom Emotion 6 at slice thickness of $0.63 \mathrm{~mm}$ (which results

143 in a three-dimensional reconstruction increment of $0.30 \mathrm{~mm}$ ). The resultant DICOM files were

144 processed by loading image files in Mimics (Materialise NV, Leuven, Belgium), and a mask was

145 created based on the threshold of bone, relative to the nominal density of air. We then created a

146 three-dimensional (3D) object from this mask, and exported the resultant file as an ASCII STL,

147 which was opened in Geomagic (ver. 2012) for final imaging edits. We also attempted to use

148 laser surface scanning (i.e., laser arm scanner) to capture 3D data, but line of sight issues with

149 overhanging morphological features and the geometric complexity of the type specimen

150 prevented a full capture of the surface geometry. As a result, we elected to use the 3D models of

151 the skull, mandibles, and scapula generated from $\mathrm{CT}$ data because this method provided

152 complete capture of the external and internal morphology. After converting the CT files into 3D

153 data, the watertight model was then processed in Autodesk Maya (ver. 2013) by Pixeldust

154 Studios (Bethesda, Maryland), decimating the models to 100,000 triangles and creating diffuse,

155 normal, and occlusion texture maps. The resultant 3D surface model datasets, processed from the

156 computed tomography scans, provided sub-millimeter accuracy, and full resolution files can be

157 downloaded at the open-access Smithsonian X 3D browser (http://3d.si.edu). These files, along

158 with supplemental ones, are also archived at Zenodo (http://zenodo.org) at the following DOI:

$159 \quad 10.5281 /$ zenodo.27214

160 


\section{Phylogenetic Analysis}

162 Recent work on the systematics of living and extinct odontocetes has recently provided several 163 phylogenetic frameworks to use in this study. Geisler et al. (2011) used a combined

164 morphological and molecular analysis to clarify the relationships among extant and fossil

165 lineages of cetaceans, with mostly a focus on odontocetes, including some important fossil taxa, 166 but taxon sampling within Inioidea was relatively sparse compared to Geisler et al. (2012). This 167 latter work, which described Meherinnia isoni Geisler et al., 2012, a late Miocene inioid from 168 marine rocks of North Carolina, U.S.A., also included other fossil inioids such as Auroracetus 169 bakerae Gibson \& Geisler, 2009, Ischyrorhynchus vanbenedeni Ameghino, 1891, 170 Protophocaena minima, and Stenasodelphis russellae Godfrey \& Barnes, 2008, some of which 171 were not included in subsequent phylogenetic analyses of odontocetes, such as the one by 172 Murakami et al. (2014). The starting point for our analysis was the matrix provided by Aguirre173 Fernández \& Fordyce (2014) in their description of the early Miocene stem odontocete Papahu 174 taitapu Aguirre-Fernández \& Fordyce, 2014, which used the morphological partition of Geisler et al. (2012) in their description of Meherrinia, along with some important modifications (e.g.,

176 the removal of Mysticeti and unpublished specimens, and coding revisions for select stem odontocetes) that enhanced its utility for resolving fossil and living odontocete relationships.

We added Isthminia as an operational taxonomic unit to the Aguirre-Fernández \& Fordyce (2014) matrix of 311 characters, and updated the character scoring for Ischyrorhynchus, which was the only inioid taxon not coded from direct observation in any previous study. The codings for Ischyrorhynchus herein were made by one of the authors of this study (CSG), who reviewed 183 all the specimens in Argentina (e.g., MLP 5-16, MACN 15135), which resulted in modifications 
184 for 20 character codings (see Supplemental File S1). The cladistic search was performed in

185 PAUP* (Swofford, 2002) using all characters as unordered. We first performed a heuristic search

186 using the tree bisection-reconnection (TBR) algorithm. In addition, we conducted statistical

187 support analyses by searching for successively longer trees to calculate decay indices and 1000

188 bootstrap replicates. The complete matrix is available in the Supplemental Information material

189 as see Supplemental File S1.

190

191 Phylogenetic Nomenclature

192 We followed the recommendations of Joyce et al. (2004) for the conversion of select ranked

193 taxonomic cetaceans names to phylogenetically defined ones in this study. The taxonomy of

194 marine mammals includes several extant monospecific forms in their own familial rank, such as

195 Eschrichtius robustus (Lilljeborg, 1861), Physeter macrocephalus Linnaeus, 1758, Pontoporia

196 blainvillei, or Lipotes vexillifer. In many of these latter cases, the conceptual basis for the higher

197 taxonomic rank includes many fossil taxa that connect the monospecific taxon to their nearest

198 living relatives, especially with stem lineages that range into geologic times that remain poorly

199 sampled and known (e.g., the Oligocene; see Uhen \& Pyenson, 2007). While it would be ideal to

200 create stem-based clade names for these single species, there remains no pathway to define pan-

201 stems based on single species, even more than 10 years after Joyce et al. (2004)'s

202 recommendations. Here we follow Joyce et al. (2004)'s logic in the specific case of the pan-stem

203 for the lineage leading to extant Inia, by forming a new pan-stem name by combining the current

204 Linnaean generic name with the prefix 'pan,' and then referred traditional family names to a

205 more inclusive clade whose composition closely resembles our current name application. For

206 these purposes, we used abbreviations NCN for New Clade Name and CCN for Converted Clade 
207 Name. Below, we clarify our precise definitions for these clades (see PhyloCode, 2014, Article

208 9.3; Cantino \& de Queiroz, 2014), and we also provide full citations for the names of specifier 209 species.

210

211 Specimens Observed

212 Auroracetus bakerae (USNM 534002), Inia geoffrensis (USNM 395415, 49582, 239667);

213 Ischyrorhynchus vanbenedeni (MACN 15135, MLP 5-16), Lipotes vexillifer (USNM 218293,

214 AMNH 57333), Meherrinia isoni (CMM-V-4051, USNM 559343, identified by J. A. Geisler),

215 Pontoporia blainvillei (USNM 482727, 482771, 482707), Stenasodelphis russellae (CMM-V216 2234).

217

218 Results

219 Systematic Paleontology

220 Cetacea Brisson, 1762

221 Odontoceti Flower, 1867

222 Delphinida Muizon, 1988a

223 Inioidea Gray, 1846 sensu Muizon 1988a

224 Pan-Inia (NCN) (panstem-based version of Inia Blainville in Desmarest 1817)

225 Isthminia, gen. nov. LSID: urn:lsid:zoobank.org:act:83F6A9B4-289D-45DE-A3D1-

226 C361DAAAF973

227

228 Definitions. 'Pan-Inia' refers to the panstem that includes crown Inia (CCN), and all other

229 lineages closer to Inia than to Pontoporia, such as Isthminia and Ischyrorhynchus. Subjective 
synonymies of Pan-Inia include: Iniidae Gray, 1846; Iniinae Flower, 1867; Saurocetidae

231 Ameghino, 1891; Iniidae Muizon, 1984; Ischyrorhynchinae Cozzuol, 1996; Iniidae Cozzuol,

232 2010; Iniidae Gutstein et al., 2014b. Crown group Inia refers to the crown clade arising from the

233 last common ancestor of all named species of Inia, including Inia boliviensis d'Orbigny 1834

234 and Inia araguaiaensis Hrbek et al., 2014. Although we follow the suggestions of the Society for

235 Marine Mammalogy’s Committee on Taxonomy (2014) in provisionally recognizing two sub-

236 species of Inia geoffrensis (I. g. geoffrensis and I. g. humboldtiana Pilleri \& Gihr, 1977), the

237 phylogenetic definition of Inia can accommodate a plurality of species and subspecies.

238

239

240

241

242

Type and Only Known Species. Isthminia panamensis, sp. nov.

Etymology. Isthm- reflects the type specimen's provenance from the Isthmus of Panama and the crucial role that the formation of this isthmus played in Earth history and evolution of the biota of the Americas. This epithet follows in the tradition of another fossil cetacean from the Chagres Formation, Nanokogia isthmia Velez-Juarbe et al., 2015. The feminine generic epithet Inia reflects its similarities to the living Amazon River dolphin (Inia geoffrensis). Pronunciation: 'Istmin-ee-a,' with the emphasis on the second syllable.

Age. Same as that of the species.

Diagnosis. Same as that of the species.

Isthminia panamensis sp. nov. (Figs. 3-12; Tables 1-3) 
LSID: urn:lsid:zoobank.org:act:A5C706B6-E0B6-43E5-A65C-E6FE0B2BDF1A

Holotype. USNM 546125, consisting of an incomplete skull, both right and left mandibles, an incomplete right scapula, and two carpals. The skull lacks the basicranium and tympanoperiotics. The holotype was collected by several of the co-authors of this study (NDP, JVJ, DV, and AO), with assistance from staff from STRI, in 2011.

Type locality. STRI locality $650009\left(9^{\circ} 16^{\prime} 55.4880^{\prime \prime} \mathrm{N}, 80^{\circ} 02^{\prime} 49.9200^{\prime \prime} \mathrm{W}\right)$, less than $100 \mathrm{~m}$ northeast of the main road in the town of Piña, along the Caribbean Sea coastline of the Republic of Panama (Fig. 2).

Formation. Piña Facies of the Chagres Formation.

Age. Microfossils place the Chagres Formation in calcareous nanofossil zone NN11 and planktonic foraminiferal zones M13b-M14, suggesting an age range between 8.52 to 5.57 Ma, i.e., Tortonian to Messinian in age (Collins et al., 1996). Hendy et al. (in press) obtained a Sr date of $\sim 7.64 \mathrm{Ma}$ from a single mollusc shell that was collected stratigraphically below the unit where the type specimen of Isthminia was discovered. This result, however, conflicts with planktonic foraminiferal data. The top of the Toro Point Member of the Chagres Formation includes co-occurring Globorotalia margaritae Bolli \& Bermudez, 1965 and G. lenguaensis Bolli, 1957 (Collins et al. 1996) indicating an astronomically calibrated age (Wade et al., 2011) of 6.13-6.08 Ma. Globoquadrina dehiscens Chapman et al., 1934 has an age range of 23.2-5.8 Ma (Wade et al., 2011) and occurs throughout the stratigraphic section, including Panama 
276 Paleontology Project locality (PPP) 1099 (Collins et al., 1996), which is located less than 1

277 kilometer from STRI locality 650009, and coeval with the type specimen of Isthminia. Because

278 the Piña Facies is stratigraphically above the Toro Member in the Chagres Formation, these

279 observations therefore constrain the age of the type specimen of Isthminia to 6.1-5.8 Ma

280 (Messinian).

281

282 Diagnosis. Isthminia is a medium sized crown odontocete (approximately $285 \mathrm{~cm}$ in total

283 length), which can be can differentiated from all other odontocetes by the following combination

284 of character states. First, Isthminia belongs in Inioidea based on: the presence of a very long

285 mandibular symphysis (c. 39[2]); a fused mandibular symphysis (c. 40[0]); a lacrimal that wraps

286 around anterior edge of supraorbital process of frontal and slightly overlies its anterior end (c.

$28751[1])$; and the maxilla forming the dorsolateral edge of the ventral infraorbital foramen (c.

$28857[1])$.

289

290

Isthminia is characterized by the following unique combination of character states among

Inioidea: rostral constriction well anterior to antorbital notch (c. 6[1]), shared with Pontoporia;

292

posterior edge of rostral edge bowed forming a deep U-shaped antorbital notch (c. 11[2]), shared with Brachydelphis spp.; small transverse distance between lateral edges of left and right premaxillae at antorbital notch (c. 66[0]), shared with Auroracetus and Inia; short posterolateral sulcus (c. 72[1]), shared with Protophocoena, Stenasodelphis, and Auroracetus; thickened anterolateral corner of maxilla over supraorbital process of frontal (c. 78[1]), shared with 
Protophocoena and Auroracetus; posterior end of premaxilla adjacent to lateral edge of nasal opening (c. 89[0]), shared with Brachydelphis spp.; suture with left and right nasals and right and left frontals shifted towards the left (c. 114[1]), shared with Pliopontos and Inia; nasals that are anteroposteriorly elongated (c. 117[0]), shared with all inioids except Ischyrorhynchus and Inia; supraoccipital below frontal and/or nasals (c. 128[0]), shared with Protophocoena, Meherrinia and Ischyrorhynchus; dorsal margin of mesethmoid at same level of premaxilla (c. 305[1]), shared with Brachydelphis mazeasi and Stenasodelphis; intermediate separation between posterior-most point of right premaxilla and nasal (c. 306[1]), shared with Pontoporia and Stenasodelphis; medial portion of maxilla on either side of the vertex face mainly dorsally (c. 307[2]), shared with Pontoporia and Pliopontos; longest side of nasal facing anterodorsally (c. 311[1]), shared with all inioids except Pontoporia (face dorsally: c. 311[0]), and Ischyrorhynchus and Inia (face anteriorly: c. 311[2]).

Among other fossil inioids in the panstem to Inia, Isthminia shares the following: with Meherrinia and Inia (not preserved in Ischyrorhynchus) three or more dorsal infraorbital foramina (c. 64[2]); with Ischyrorhynchus, premaxillae on anterior two thirds of rostrum contact along the midline for nearly their entire length (c. 9[0]), tooth enamel with reticular striae (c. 26[1]), and anterior edge of nasals in line with posterior half of supraorbital processes (c. 80[4]); with Inia and Ischyrorhynchus supraorbital processes of frontal that slope laterodorsally away from vertex (c. 46 [2]), transverse width of nasals within 10\% of nares width (c. 119[2]), nasals elevated above rostrum relative to lateral edge of maxilla (c. 123[1]), and frontals higher than nasals (c. 124[2]); with Inia the following synapomorphies: posterior buccal teeth that are nearly an equilateral triangle (c. 30 [1]), small lacrimal (c. 50[0]), small exposure of the lacrimal and 
322 jugal posterior to the antorbital notch (c. 55[0]), posterior portion of nasals elevated above

323 rostrum (c. 123[1]), frontals posterior to nasals with same width as nasals (c. 125[1]), maxilla on

324 dorsal surface of skull does not contact supraoccipital posteriorly (c. 129[0]), and dorsal edge of

325 zygomatic process with distinct dorsal flange (c. 143[1]).

326

327 Lastly, Isthminia displays the following apomorphies: maxilla and premaxilla fused along most 328 of rostrum (c. 10[0]); lower number of mandibular teeth (18) (c. 37[5]); dorsal edge of orbit low 329 relative to lateral edge of rostrum (c. 47[1]); premaxilla is convex transversely anterior to nasal

330 openings (c. 68[1]); posterior-most end of ascending process of premaxilla in line with posterior

331 half of supraorbital process of frontal (c. 74[2]); very narrow width of posterior edge of nasals (c.

$332120[3]$ ); slight emargination of posterior edge of zygomatic process by sternomastoid muscle

333 fossa (c. 144[1]); and dental roots that are elongate, rugose, bulbous, and much larger than the

334 tooth crowns, with some roots that have their apices oriented posteriorly so that they come close

335 to the anterior end of the root of the succeeding tooth.

336

337 Etymology. The species epithet recognizes the Republic of Panama, its people, and the many 338 generations of scientists who have studied its geological and biological histories.

Description

341 Skull

342 The skull of Isthminia is relatively complete on its dorsal aspect, although it is missing the left

343 side of the facial bones (Fig. 3). The skull is heavily eroded along its ventral surface, and the

344 basicranium is absent except for a small portion of the right parietal and right alisphenoid (Fig. 
345 4). The skull preserves most of the dorsal aspect of the supraoccipital, including small portions

346 that articulate with the vertex and nuchal and sigmoidal crests (Fig. 3A-C). Overall, the profile of

347 the skull is dominated by the rostrum (Fig. 5), which is complete and comprises approximately

$34875 \%$ of the length of the preserved skull (the rostrum length is $36.6 \mathrm{~cm}$; Table 1). The anterior

349 portion of the rostrum is slightly displaced by both an oblique and transverse fractures, likely

350 from geologic compaction or other diagenetic factors, which displace the elements

351 approximately 1-2 $\mathrm{mm}$ from their life positions. Most of the upper dentition is missing from the

352 skull, except for the anterior teeth, some of which are complete; other more posterior teeth are

353 incomplete, while three isolated teeth were recovered from the quarry at the type locality.

354 Despite the heavy erosion that removed most of the left portion of this skull, sufficient

355 anatomical details are preserved on the right side of the cranium, and along the rostrum to

356 provide insights into the morphology of Isthminia.

357

358 Premaxilla. In dorsal view, the premaxilla dominates the visible part of the rostrum, comprising

359 the entirety of the rostrum from its anterior end to about $75 \%$ of the length of the rostrum. In this

360 view, the premaxilla occupies a width greater than that of the maxilla until the level of the

361 maxillary flange (sensu Mead \& Fordyce, 2009:62), where the width of the premaxilla begins to

362 taper relative to the expansion of the maxilla overlying the cranium, in dorsal view (Fig. 3).

363 Along the rostrum, anterior of the premaxilla-maxilla suture, there are several shallow

364 longitudinal canals that terminate in small oval foramina ( $\sim 5 \mathrm{~mm}$ long by $\sim 2 \mathrm{~mm}$ wide). These

365 canals are similar to those observed in adult specimens of Inia, but markedly different from the

366 singular, deep groove that separates the posterior connection of the premaxilla and maxilla in

367 Pontoporia, Ischyrorhynchus, immature specimens of Inia, and Lipotes. In Isthminia, adult Inia 
and Lipotes, these canals disappear posteriorly, as the premaxilla-maxilla suture becomes seamless along the length of the rostrum (Figs. 3 and 5).

The paired right and left premaxillae are unfused for $4 \mathrm{~cm}$ at their anterior tip (Fig. 3A,B,D), presenting a slight gap, which is likely homologous in other odontocete taxa with the mesorostral groove (sensu Mead \& Fordyce, 2009:16). This gap is then obscured posteriorly by full sutural fusion between the premaxillae for $24 \mathrm{~cm}$ along the midline of the rostrum until an elongate $(6.9$ cm-long) window is exposed between the overarching right and left premaxillae, just anterior of the level of the antorbital notches (Fig. 3A,B). Near the anterior origin of this window, the anteromedial sulcus appears, approximately at the transverse level of the last upper tooth alveolus (Fig. 4). This latter sulcus extends subparallel to the latter window until it terminates posteriorly in the premaxillary foramen. In Inia, the anteromedial sulcus extends farther anteriorly, and the portion of the premaxilla medial to the sulcus is more bulbous, while in Pontoporia the anteromedial sulcus is deeper, and nearly enclosed dorsally by overhanging flanges of the premaxilla. Fossil pontoporiids are broadly similar to Pontoporia, whereas in PanInia, such as Ischyrorhynchus and Meherrinia, this area is not well preserved. At the level of the premaxillary foramen, the right and left premaxillae diverge from their midline fusion in separate paths around the external bony naris (Fig. 6). This divergence produces a V-shaped gap, $32 \mathrm{~mm}$ in anteroposterior length and $9 \mathrm{~mm}$ in lateral width, which is narrowed and longer than fossil pontoporiids, such as Auroracetus; this gap is small and variable in Inia, and broad and triangular in Ischyrorhynchus and Meherrinia. 
390 The premaxillary foramen itself is thinly ovate, $11 \mathrm{~mm}$ anteroposterior length, and $4 \mathrm{~mm}$ wide

391 (Fig. 6), unlike the small, subcircular foramina in other fossil inioids. (The left side of the

392 cranium, from this level posteriorly is not preserved, and thus the remainder of the description

393 necessarily uses the right side of the cranium). The posterolateral sulcus is shallow, and extends

394 slightly laterally from its deepest portion at its origin, the premaxillary foramen. The

395 posterolateral sulcus terminates posteriorly in a faint way at the level of the anterior margin of

396 the external naris. This condition is similar to Meherrinia and Brachydelphis, while it is different

397 from Pontoporia, Auroracetus, Pliopontos, Pontistes and Inia, which present a deeply excavated

398 sulcus along the posterolateral edge of the premaxilla. This portion of the premaxilla is not well

399 preserved in Ischyrorhynchus. Medially, the posteromedial sulcus is unusual in originating $9 \mathrm{~mm}$

400 posterior of the premaxillary foramen and bifurcating into lateral and medial tracts that delineate

401 the borders of the premaxillary sac fossa. Along with the posterolateral sulcus, these bifurcating

402 tracts create a Z-shaped sulci pattern that is shallow laterally and deep ( $>3 \mathrm{~mm})$ anteromedially

403 (Fig. 6B). The path of medial tract of the posteromedial sulcus extends along the lateral margin

404 of the anterior half of the external naris, but it is not confluent with the border of the naris. This

405 morphology is completely new, and not observed in any inioid nor delphinidan. The bifurcating

406 tracts enclose a low, but convex premaxillary sac fossa located lateral to the external naris and

407 dipping medially, whereas the premaxillary sac fossa in all other inioids is located anterolateral

408 of the external naris and is strongly convex, except for Meherrinia and Pliopontos. This portion

409 is not preserved in Ischyrorhynchus. The premaxillary sac fossa in Lipotes is flat, with elevated 410 margins.

411 
412 The patent posterior termination of the entire premaxilla is spatulate, flat, and it appears at the

413 level of the posterior half of the external bony naris, as in Meherrinia. There is an $8 \mathrm{~mm}$

414 separation between the posteomedial termination of the premaxilla and the anterolateral-most

415 point of the nasal. In contrast, the posterior termination of the premaxillae of Pontoporia reaches

416 the level of the posterior edge of the external nares, while in adult Brachydelphis spp.,

417 Pliopontos, Pontistes, Inia, and Lipotes, it extends even farther posteriorly; in young specimens

418 of Brachydelphis and Pontoporia, it is in an intermediate position. Although there is slight

419 erosion of the bony surface along the immediate margin of the external naris, the gap between

420 the premaxilla and nasal is patent.

422 Maxilla. Throughout most of the anterior two thirds of the rostrum, the maxillae and premaxillae 423 have a cylindrical outline (Fig. 3). Dorsally, the maxilla is exposed slightly on the lateral margin 424 of the rostrum that is otherwise dominated by the premaxilla until about the proximal third of the 425 rostrum where the maxilla becomes flatter along the maxillary flange. (As with the premaxilla, 426 nearly all of the facial portion of the left maxilla has been lost to erosion, and the description is

427 based on the right side). The antorbital notch is widely open, U-shaped, and oriented anteriorly.

428 Posterior to the antorbital notch, the maxilla is expanded to cover most of the supraorbital 429 process of the frontal, with the exception of the posterior-most and posteromedial edge, where 430 the frontal is exposed. This posteromedial exposure of the frontal is similar to the condition 431 observed in Ischyrorhynchus and Inia (mainly in juveniles), and differs from Pontoporia, 432 Pontistes, Pliopontos, Meherrinia, Brachydelphis spp., and Lipotes, where the maxillae reaches 433 the nuchal crest, and the lateral edges of the vertex. Posterolateral to the antorbital notch, the 434 maxilla form a low maxillary crest (sensu Mead \& Fordyce, 2009:51), which extends from the 
435 preorbital process, continues along the length of the supraorbital process of the frontal, but

436 terminates at the postorbital process, unlike in Inia, where the crest continues well posterior of

437 the postorbital process and join the temporal crest. In Isthminia, the maxillary crest is

438 mediolaterally thicker $(2-6 \mathrm{~mm})$, but lower $(\sim 5 \mathrm{~mm})$, than the thinner, but higher $(>5 \mathrm{~mm})$ crest

439 observed in Inia; in Pontoporia and Pliopontos this crest extends only the length of the

440 supraorbital process.

441

442 Dorsally, the right maxilla shows a large diameter $(\sim 10 \mathrm{~mm})$ anterior dorsal infraorbital foramen,

443 located at the level of the antorbital notch (Figs. 3A,B,D and 6). A second, anterior dorsal

444 infraorbital foramen is posterolateral to the first one, and it is smaller in diameter $(\sim 7 \mathrm{~mm})$, and

445 oriented posterolaterally. A single, posterior dorsal infraorbital foramen is located posterolateral

446 to the external nares, it has a diameter of about $9 \mathrm{~mm}$ and its orientation is posterodorsal. The

447 posterior dorsal infraorbital foramen of Isthminia is absolutely larger and located farther

448 posteriorly than the corresponding foramen in Inia, Ischyrorhynchus, Meherrinia, Brachydelphis,

449 Pontistes, Pliopontos, Pontoporia, and Lipotes.

450

451

452

In ventral view, the rostral portion of the maxilla bears alveoli for at least 14 maxillary teeth, with thin interalveolar septa (Fig. 4). At the ventral midline contact between the maxillae, there is a longitudinal groove that extends from anteriorly to about the level of the fifth maxillary tooth; a similar sulcus is also observed in Inia and Pontoporia, whereas this groove reveals a palatal exposure of premaxilla and/or vomer in Ischyrorhynchus and Brachydelphis mazeasi. Along the ventral surface and anteromedial to the jugal, there is a shallow $(\sim 2 \mathrm{~mm})$ oval $(\sim 17$ $\mathrm{mm}$ long by $10 \mathrm{~mm}$ wide) fossa; a similar fossa is also present in some specimens of Inia, 
458

459

460

461

462

463

464

465

466

467

468

469

470

471

472

473

474

475

476

477

478

479

480

Ischyrorhynchus, Brachydelphis spp. and very slightly Pontoporia. Medial to this shallow fossa, which we term the ventral maxillary fossa, there is an elongated fossa that continues anteriorly parasagittally for about $60 \mathrm{~mm}$, and $5 \mathrm{~mm}$ in width and depth. The location and morphology of this latter fossa corresponds to the anterior sinus of Inia (Fraser \& Purves, 1960), and it is exposed in Isthminia because its overlying maxilla and palatine were eroded. An anterior sinus is also found in Ischyrorynchus, however it is shorter than that in Inia and Isthminia. The rostral portion is not preserved in the other genera of inioids, preventing any comparison.

Lacrimal and Jugal. The lacrimal appears to be ankylosed with the anterior margin on the supraorbital process of the frontal, forming its anterior surface, a condition common to all adult inioid specimens (Figs. 3-5). Ventrally, the lacrimal extends medially to join the jugal, which together forms the anteroventral surface of the antorbital notch. The preserved part of the jugal is a thin strut that is subcylindrical in outline ( 4 mm wide; $17 \mathrm{~mm}$ long; $\sim 2 \mathrm{~mm}$ thick) and oriented posteroventrally. Overall, it is very similar in morphology to the jugal of Inia.

Frontal. Dorsally, the frontal is mostly covered by the maxilla, but it is exposed along the posterior and posteromedial edges of the skull roof (Figs. 3 and 5-7). In Isthminia, the right and left frontals form the highest part of the vertex, and together form a pair of rounded, rectangular knobs with a slight midline cleft (Figs. 3A-C,5 and 6). This topographic high for the frontals at the vertex is similar in Inia, Ischyrorhynchus or Meherrinia, and even Pontoporia and Lipotes, although the frontals in Isthminia are small and low by comparison with Pan-Inia. Unlike Inia and Meherrinia, the midline cleft between the right and the left frontals at the vertex does not show participation of an anterior supraoccipital (or possibly interparietal) wedge externally nor 
481 in internal CT scan data (Fig. 7 and Supplemental Video S1). The dorsal surface of the vertex is

482 lightly rugose, but not as strongly as in adult specimens of Inia.

483

484 The supraorbital process is dorsoventrally thin $(\sim 5 \mathrm{~mm})$ with a blunt preorbital process; in 485 contrast, the postorbital process is more elongated with a triangular cross section through its 486 longitudinal axis, similar to the general condition of the other inioids. Nevertheless the distance 487 between this two processes $(52 \mathrm{~mm})$, reflecting the size of the orbit, is about twice that of adult specimens of Inia, but in Isthminia it is proportionally similar to the other fossil inioids (all known specimens of Ischyrorhynchus lack this feature; see Table 3). In dorsal view, the lateral edge of the supraorbital process is relatively straight and oriented parasagitally, unlike Inia and

Pontoporia where this border is laterally concave and oriented anterolaterally, or the nearly straight but anterolaterally oriented borders of Pliopontos and Brachydelphis. Additionally, the postorbital process is shorter than the length of the orbit, contrasting with the much longer process and smaller orbit in Inia. The ventral surface of the supraorbital processes is gently concave with a low, but distinct postorbital ridge. Medially and posterior to the frontal groove there is a shallow $(<1 \mathrm{~cm})$ round $(\sim 1.5 \mathrm{~cm}$ diameter $)$ fossa for the postorbital lobe of the pterygoid sinus. This same fossa varies tremendously in adult specimens of Inia, where it can either be shallow and slit-like (e.g., USNM 49582) or form a deep pit (e.g., USNM 239667). By contrast, this fossa in Pontoporia is deep, rounded and floored posteroventrally by the alisphenoid; in Brachydelphis spp., this fossa is shallow, as it is in Lipotes.

In the ventral view of the endocranium (Fig. 4), the right and left frontals surround the anterior aspect of the endocranium, where the extensive cerebellar juga are preserved on the ventral 
504 surface (Mead \& Fordyce, 2009:18). Medially, the posteromedial margins of the frontals inside

505 the endocranial region enclose a deep dorsal sagittal sinus sulcus along the midline. Such a

506 structure is not visible in intact, extant skulls of Inia and Pontoporia, available for observation,

507 nor is it preserved in most fossil inioids. Incomplete crania of Brachydelphis referable to $B$.

508 jahuayensis (Gutstein et al. 2009:fig. 7B) show no such sinus, but instead a low, bony ridge.

509 Finally, a small wedge of the supraoccipital directly ventral to the vertex separates the fan-like

510 posterior-most margins of the right and left frontals, which eventually contact the anterodorsal

511 margins of the parietals along the frontoparietal sutures.

512

513 Nasal. The right and left nasals are paired at the vertex, sloping away from the topographic high 514 of the paired frontals (Figs. 3,5 and 6). Overall, the nasal is large (width $=\sim 12 \mathrm{~mm}$; length $=41$

$515 \mathrm{~mm}$ ), dominating the anterodorsal surface of the vertex, and occupying the entire posterodorsal

516 margin of the external bony naris. The anterior margin of nasal is concave. Together, the right

517 and left nasals are anteroposteriorly elongate with some tapering posteriorly, as in Pontoporia,

518 Brachydelphis, Pontistes, Auroracetus, Pliopontos. However, the nasal in Isthminia is

519 dorsoventrally more massive than these latter genera, and it is not as anterodorsally inclined as in

520 Meherrinia not as anterior-facing as in Ischyrorhynchus, Inia, and Lipotes.

521

522 The anterior margin of the nasal displays a low sigmoidal crest that extends transversely with a

523 small protuberance that rises in the middle of the nasal, about $10 \mathrm{~mm}$ from its anterior margin;

524 with the paired right and left nasals, these small crests and the base of these protuberances

525 outline a wide, but shallow V-shaped concavity, pointing posteriorly (Fig. 3A,B,D). The

526 posterior margin of the nasal is difficult to resolve without close inspection because the sutural 
527 distinction between the nasal and the frontal in this part of the vertex is overlapping and thin (see

528 also Fig. 6). The posterior termination of the nasal overlaps with the frontal by passing in a

529 broadly posteromedial path, terminating anterior of the level of the posteriormost margin of the

530 maxilla. Together, the posterior termination of the right and left nasals show an anteriorly-

531 pointed V-shaped margin. This condition is similar to Pontoporia and Brachydelphis, where the

532 contact between the nasal and frontal shows a similar V-shaped margin; in Auroracetus and

533 Meherrinia, a small wedge of the frontals insert medially between the nasals.

534

535 Vomer and Ethmoid. The vomer is poorly preserved ventrally, but a small portion is patent

536 along the midline palatal surface adjacent to the medial margin of the highly eroded right

537 maxilla, approximately extending $45 \mathrm{~mm}$, with an anterior extent to the transverse level of the

538 8th maxillary tooth alveolus (Fig. 4). The ethmoid is incompletely preserved; the crista galli is

539 shallow with very small $(<1 \mathrm{~mm})$ foramina in its surface. The ethmoid forms the bony nasal

540 septum, rising dorsally to the same horizontal level as the premaxillae, but not quite reaching the

541 level of the nasals. The lateral wings form the posterior and posterolateral walls of the external

542 nares, which are cleanly separated from the anterior margin of the nasals by a continuous gap 5-8

543 mm wide (Fig. 6).

544

545 Parietal. The parietal is exposed broadly on the posterior margin of the temporal fossa, along

546 with the frontal and squamosal (Figs. 3C,D,5 and 7). The lateral surface of the parietal is smooth

547 and convex; in posterior view, the temporal crest of the parietal is posterolaterally oriented, as

548 opposed to the ventrally oriented crests in Inia and Pontoporia. The anterior extent of the parietal

549 is unclear because the parieto-frontal suture is not patent, similar to adult specimens of Inia. 
551 Supraoccipital. Only the dorsal half of the supraoccipital can be reliably determined for Isthminia. Dorsally, the supraoccipital does not participate in the vertex, but participates in the temporal and nuchal crests (Fig. 3A-C); the nuchal crest is transversely straight, about $10 \mathrm{~mm}$ thick, and unlike the more anteromedially oriented crest in Inia and the posteriorly concave crest of Pontoporia. Posteriorly, there is a midline external occipital crest that is bounded laterally by deep (9 mm) semilunar fossae; such fossae are also patent in adult specimens of Inia and Pontoporia. The external surface is smooth and convex. The temporal crests are nearly vertical, and dorsally they join the nuchal and orbitotemporal crests (sensu Fordyce 2002:194), forming a tabular, triangular surface at the triple junction. When viewed posteriorly, the supraoccipital has a square outline, unlike the more sub-triangular outline in Inia, or the general pentagonal outlines of Pontoporia and Lipotes.

Squamosal. The right squamosal is nearly completely preserved. The zygomatic process of the squamosal is relatively long, mediolaterally thin, laterally convex, and medially concave.

Overall, its main corpus is rectilineal in lateral view, in contrast to the gently tapering profile of Pontoporia and acute tapering in Inia. In Isthminia, the anterior tip of the zygomatic process is expanded, with a squared-off anterior margin, more like Inia, and to a lesser degree Brachydelphis mazeasi, rather than the rounded, tapering tip of Pontoporia and Pliopontos. The dorsal surface of the root of the zygomatic process in Isthminia is concave, while its lateral edge flares outward about $10 \mathrm{~mm}$ farther laterally than the anterior part of the process (Figs. 3-5). In lateral and ventrolateral views, the postglenoid process is not patent, but it shows no indication

572 of supporting elaboration, such as the bulbous postglenoid process in both Inia and Pontoporia, 
573

574

575

576

577

578

579

580

581

582

583

584

585

586

587

588

589

590

591

592

593

594

595

85

and acute and thin in Brachydelphis spp. (Gutstein et al., 2009; Lambert \& Muizon, 2013).

Ventrally, the outline of the glenoid fossa in Isthminia is elongate, shallowly convex, and faces ventromedially. The tympanosquamosal recess extends as a deep $(\sim 5 \mathrm{~mm})$ sulcus medial to the glenoid fossa, as it does in other inioids. The posterolateral surface of the squamosal has a broad and relatively deep concave sternomastoid fossa, deeper than Inia.

The squamosal plate is relatively low, occupying only about the lower quarter of the surface of the temporal fossa, which is dominated by the parietal (Fig. 5). This configuration is similar to the condition seen in Pontoporia and Brachydelphis, but contrasts with Inia, where the squamous portion is much higher, a condition also visible in Lipotes. The anterior extent of the squamosal plate is ankylosed with the posteroventral edge of the temporal wall exposure of the alisphenoid in the type specimen of Isthminia.

Alisphenoid. Only the dorsal portion of the alisphenoid is preserved in the type specimen of Isthminia above the horizontal level the squamosal fossa (Fig. 5). In lateral view, the parietoalisphenoid suture extends in a path from the squamosal plate at the posterior margin of the temporal fossa dorsally to a level in line with the nuchal crests; in this way, this sigmoidal suture partitions the parietal (dorsally) and the alisphenoid (ventrally) in the middle of the temporal fossa. The anterior margin of the alisphenoid extends at least to the level of the postorbital processes of the frontal, although the actual sutures are not patent at the anterior end (see also Fig. 7). In lateral view, the dorsal extent of the alisphenoid on the temporal wall is much greater than that seen in Inia, but we note a degree of variability in Inia. 
Mandible

Both right and left mandibles are preserved intact and remain articulated via an osseous symphyseal articulation (Figs. 8 and 9; Class IV jaw joint of Scapino, 1981). The length of the mandibular symphysis $(21.0 \mathrm{~cm})$ is approximately $43 \%$ of the entire length of the mandible. The mandibles possess nearly all of the original lower teeth; the lower first incisors are missing, along with posterior most three teeth of the right mandible (although one isolated tooth is a perfect fit for $\mathrm{PC}_{12}$; see Fig. 10). Both the right and left mandibles possessed 18 and 17 lower teeth, respectively, although the degree of bone remodeling posterior of left $\mathrm{PC}_{13}$ leads us to presume that 18 teeth is the likely maximum lower tooth count (Fig. 10). Posterior margins are incomplete for both sides of the mandible, and the left angular process appears intact and there is a weak suggestion of the osteological structure where the left articular condyle would have been. The right articular condyle is missing. Most of the mandibles are well preserved, although much of the right acoustic window is degraded from erosion and/or diagenesis (Fig. 9).

In anterior view and posterior views (Fig. 8C,D), the mandibles show slight asymmetry in the relative directions of the overall mandibular rami, with the right ramus extending laterally and slightly ventral relative to the left one. This asymmetry may be diagenetic and related to sediment compaction, but we think it more likely records the original right-left asymmetry that is common in other living inioids (Werth, 2006), and this condition is evident in adult specimens of Pontoporia, with its proportionally elongate rostrum. In ventral view, the anterior termination of the mandibles from the gnathion to pognion is gradual and not acute, with a ventral outline that is somewhat rectangular. Anteriorly, this termination is flat and not acute. Posteriorly, the ventral surface of the mandibles is U-shaped, in transverse section, through the symphysis. Generally, 
619 this morphology is most similar to that of Inia, and Saurocetes argentinus Burmeister, 1871,

620 which is only known from a mandibular fragment that is less complete than Isthminia (Cozzuol,

621 1989; Cozzuol, 2010). The general lateral and horizontal profiles of the mandible in Isthminia

622 are unlike Pontoporia, with a deep lateral groove, and unlike the strongly convex mandibles of

623 Brachydelphis mazeasi (based on MUSM 887).

624

625 The ventral margins of the mandible, posterior of the symphysis, are rounded until the posterior 626 half of the level of the acoustic window when this margin gradually gains an edge (Fig. 8D). The

627 medial profile of the acoustic window in Isthminia is dorsoventrally narrower than that of Inia, 628 and considerably more acute than Pontoporia. Both right and left mandibles show approximately

6297 mental foramina each, spaced along the ventrolateral margins of the mandibles along the 630 symphysis. In each case, the foramina open anteriorly, often forming sulci with long tails. The 631 anterior most foramina are paired close to the midline of the symphysis at the level in between 632 the third and fourth lower tooth. Isthminia shares a high number of mental foramina with Inia, 633 whereas both Pontoporia and Brachydelphis mazeasi shows fewer (1-2 mental foramina in adult 634 specimens of Pontoporia, and 4 mental foramina in MUSM 887).

636 The overall morphology of the mandibles in Isthminia shares the most similarities with Inia, 637 among inioids and delphindans for which this element is known, especially in lateral and 638 horizontal profiles anterior to the symphysis. Posterior of the symphysis, the rami of the 639 mandibles are lower than Inia, and slightly more gracile. The mandibles of Isthminia are also not 640 dorsoventrally flattened like those of Pomatodelphis inequalis Allen, 1921, nor are they slender 641 like those of Kentriodon pernix Kellogg, 1927 (USNM 8060) and Brachydelphis mazeasi (based 
642

643

644

645

646

647

648

649

650

651

652

653

654

655

656

657

658

659

660

661

662

663

664

on MUSM 887). The mandibles of Isthminia differ strongly from Lipotes, and fossil delphindans such as Lophocetus pappus Kellogg, 1955 (USNM 15985) and Hadrodelphis calvertense

Kellogg, 1966 (USNM 23408, 189423), which all notably have many more teeth posterior of the symphysis, and exhibit rounded, nearly circular alveoli. Ovate alveoli are notable in putative inioids represented by fragmentary mandibles, such as Saurocetes argentinus and Hesperocetus californicus True, 1912 (UCMP 1352), although the dentition of Isthminia is far less bulbous than either. In Goniodelphis hudsoni, another putative inioid, the mandibles are relatively deeper, and mediolaterally flattened, with a much longer symphysis, and mediolaterally flattened teeth that are triangular in outline when viewed laterally, and with crowns are much more slender and somewhat recurved (see below).

\section{Dentition}

Upper. The upper dentition consists of 15 teeth per side, counted by alveoli in the premaxilla and maxilla on the right side of the skull. It is less complete than the lower dentition. Of the original upper dentition, only a total of 14 teeth remain preserved in their alveoli, with 6 in the left side and 8 in the right. Of these intact teeth, the right side preserves only the 2 distalmost teeth with crowns, while the others only preserve the tooth roots, with fractures at the base of the crown that are probably postmortem. An isolated upper right tooth discovered during excavation fits well in the third postcanine $\left(\mathrm{PC}^{3}\right)$ alveolus, and the lack of any preserved alveoli posterior to this level increases the likelihood of this placement being correct, although there is no way to eliminate a more posterior placement (see Fig. 10). Another isolated tooth root lacking the crown likely belongs to a right alveolus in the posteriormost dentition that is not preserved on this side of the skull. The left side preserves intact teeth, with crowns, from the first incisor $\left(\mathrm{I}^{1}\right)$ to $\mathrm{PC}^{1}$ and 
665 then an open alveolus at $\mathrm{PC}^{2}$, followed by two tooth roots with rounded breaks where crowns 666 were likely present prior to death. Right $\mathrm{PC}^{7}$ is intact, although all of the other alveoli on this 667 side are missing their teeth.

668

669 Overall, the teeth have slightly anteroposteriorly expanded tooth roots, exhibiting an ovate 670 outline in occlusal profile at the margin of the alveolus, which is very similar to Goniodelphis, 671 Hesperocetus and Ischyrorhynchus, although Isthminia has more clearly ovate tooth alveoli than

672 all of these. By comparison, Inia and Lipotes have subcircular tooth outlines at the alveolar 673 margins, whereas Pontoporia show nearly rectangular outlines. The posterior roots of the upper 674 teeth are somewhat gibbous, with closed pulp cavities distally. The exposed base of the tooth 675 roots, ventral of the level of alveolar margin, tapers dramatically towards the base of the tooth 676 crown, with the crown situated more or less centrally on the tooth root, except for the anteriormost pairs of incisors, which are slightly procumbent. The base of the upper tooth crowns range from 11-12 $\mathrm{mm}$ in diameter, with very light longitudinal striae that surround the perimeter of the base (such light striations are visible on both lower and upper teeth). The enamelocementum boundary between the roots and the crown is distinct and sharp for both upper and lower teeth. The apices of the upper tooth crowns are worn, leaving subcircular tooth wear outlines through the enamel into the dentin that is polished. With the exception of the first 683 incisors, the crowns of the upper dentition exhibit a slight buccal curve. Wear facets can be noted on the posterior margins at the base of the tooth crown in the first incisors and on the anterior 685 side of right $\mathrm{PC}^{1}$. 
687 Lower. The lower dentition is nearly complete, consisting at most of 18 teeth per side, and 688 missing only the first lower incisors and the two posteriormost left postcanine teeth. The right 689 side consists of 18 teeth, whereas the left side consists of 17 teeth, although there are signs of 690 bone remodeling where the alveolus of $\mathrm{PC}_{14}$ may have been. An isolated lower left tooth found 691 during discovery quarrying fits reasonably well in the left $\mathrm{PC}_{12}$ alveolus, and the morphology 692 and wear on the tooth crown matches its intact right counterpart (see Fig. 10). Like the upper 693 dentition, the lower teeth posterior of the incisors are broadly ovate in occlusal profile, formed 694 by the margins of the alveoli.

695

696 The near complete lower dentition provides detailed information about the morphology of the 697 tooth crowns throughout the mandible for which the upper dentition only provides limited 698 information. While the lateral profile of the lower dentition shows that the teeth are generally 699 oriented vertically, but viewed along the major axis of the mandible, the anterior teeth from the 700 canine $\left(\mathrm{C}_{1}\right)$ to $\mathrm{PC}_{3}$ show buccal curvatures with slight lateral compression and mesiodistal keels that grade into straighter teeth without mesiodistal keels posterior of $\mathrm{PC}_{3}$ and that also have more 702 apical tooth wear, leaving less of the original tooth crowns. Generally, lower dentition posterior of $\mathrm{PC}_{3}$ are rounder in occlusal profile, with slight lingual protuberances on the crown beginning at $\mathrm{PC}_{6}$ that become more patent as true lingual cusps posterior of $\mathrm{PC}_{9}$. After this level, the lower teeth grade slowly to presenting a more lingual orientation. Posterior of the termination of the mandibular symphysis, the diastemata shorten between adjacent lower teeth, although there is still enough space between the posterior most teeth to permit interlocking occlusion with the corresponding upper dentition. Most of the lower teeth lack non-occlusal wear facets, except for the right $\mathrm{I}_{2}$ and left $\mathrm{PC}_{9}$. 
711 Careful manual articulation of the lower jaw with the rostrum using full size 3D prints of the

712 type specimen shows that the lower and upper dentition interlock in a precise, alternating way

713 similar to extant odontocetes (e.g., Tursiops Gervais 1855) with robust dentition. Although both

714 lower teeth and upper teeth have crown base diameters in the same range (11-12 $\mathrm{mm}$ in

715 mesiodistal diameter), the slightly shorter lower dentition diastemata provides the space for

716 upper and lower teeth to slide past one another. Unusually, $\mathrm{I}_{2-3}$ together pass posterior and

717 anterior of $\mathrm{I}^{1-2}$, respectively, although such imprecise occlusions do occur in other odontocetes, 718 and such a similar pairing in the dentition can be observed in Inia (the posterior lower teeth of 719 USNM 49582).

720

721 Scapula

722 Only the right scapula is preserved in the type specimen of Isthminia (Fig. 11). In dorsoventral 723 dimensions, the preserved element is $16.8 \mathrm{~cm}$ tall, and approximately $15 \mathrm{~cm}$ in anteroposterior

724 length. The scapula is incomplete, and the following parts are missing from the type specimen:

725 most of the dorsal margin, and especially most of the anterior aspect; most of the acromion; and

726 the anterior tip of the coracoid process. The posterior margin of the suprascapular border is

727 intact, as well as the glenoid fossa and most of the region surrounding the ventral aspect of the 728 scapula.

729

730 The scapula is broadly fan-shaped, although it is exceedingly thin along the broken dorsal

731 border, ranging from 1-3 mm in mediolateral thickness (Fig. 11). Nearly the entire part of the

732 scapula housing the supraspinous fossa is missing, and only the basal $2 \mathrm{~cm}$ of the spinous 
733 process at its L-junction with the base of the acromion is preserved. The infraspinous fossa is

734 deep, and it is the most concave aspect of the scapular topography in lateral view. Consequently,

735 in medial view, the costal surface of the scapula shows corresponding and marked convexity.

736 The depression for the teres major muscle is shallow, but patent. In dorsal view, the most striking

737 aspect of the scapular morphology is the sinusoidal profile of the dorsal border created by the

738 deep infraspinous fossa.

739

740 The acromion is incomplete, but the preserved base shows that it was dorsoventrally tall $(25 \mathrm{~mm})$

741 relative to the same dimension of the coracoid process, thin (4 $\mathrm{mm}$ in mediolateral thickness),

742 and curved medially from its base; reminiscent of the condition observed in Inia. This

743 morphology differs from the anteriorly rounded, subtriangular outline of the acromion of

744 Brachydelphis mazeasi (MUSM 887) and Pontoporia, where the proximal end of the acromion is

745 dorsoventrally broad and tapers distally. In lateral view, the angle formed by the acromion and

746 the spinous process in Isthminia is nearly 90 degrees, and the anterior margin of the scapular

747 border bisects this angle at about 70 degrees from the dorsal margin of the acromion. The

748 coracoid is stepped medially from the level of the acromion, and it is thicker laterally than the

749 acromion, with a slight lateral curve, and presents a slightly spatulate anterior termination, which

750 is typical in delphinidans.

751

752 The glenoid fossa is $13 \mathrm{~mm}$ deep at its deepest, relative to its ventral margins. In ventral view,

753 the overall shape of the glenoid fossa is roughly that of a slightly laterally compressed oval (Fig.

754 11E-F); when combined with its depth, the overall topography of the glenoid fossa is reminiscent 
755 of an ice cream scoop. A sharp posterior margin of the posterior scapular border extends to the

756 margin of the glenoid fossa.

757

758 Carpals

759 Two carpal elements were collected in close proximity to the cranial elements of Isthminia,

760 disarticulated and in isolation (Fig. 12). Both elements are mediolaterally flattened with anterior,

761 posterior, proximal, and distal surfaces that are shallowly concave to convex, forming articular

762 surfaces with the radius, ulna, other carpals, or metacarpals. Both carpal elements also have one

763 surface that is well preserved, while another that is highly eroded. It is difficult to side carpal

764 isolated cetacean carpal elements; the only other preserved postcranial element is the right

765 scapula, which provides one argument for considering these isolated elements as belonging to the

766 right side, although we cannot exclude the possibility that they each belong to different sides.

767

768 We compared these two isolated carpals with an articulated forelimb of Inia geoffrensis (USNM

769 395602, see Fig. 12) as well as with other odontocetes (Cooper et al., 2007). The smallest carpal

770 element (Fig. 12B) represents either the cuneiform or the pisiform. It has a roughly lozenge

771 outline, and it is about $50 \%$ smaller than the larger carpal element, which makes its identity as

772 the pisiform more likely, given its association with the larger carpal. Interpreted as a pisiform, its

773 anterior and distal surfaces are flat and likely articulated with the cuneiform and metacarpal V,

774 respectively. A small pisiform is observed in Inia, as well as in other delphinoids (Cooper et al.,

775 2007), while it seems to be lost in other, more distantly related river-inhabiting taxa (e.g.,

776 Platanista gangetica, USNM 172409). The larger carpal (Fig. 12C) has an irregular pentagonal

777 outline, which limits its identity to the unciform, cuneiform, or lunate. The proximal facets of the 
778

779

780

781

782

783

784

785

786

787

788

789

790

791

792

793

794

795

796

797

798

799

800

unciform and cuneiform articulate with metacarpals IV and V, respectively. Given the length of the longest articular facet of this element, in direct comparison with the articulated forelimb of Inia (USNM 395602), we propose that this element most likely corresponds to the unciform.

\section{Phylogenetic Analysis}

We obtained six most parsimonious trees (length $=1922$; ensemble consistency index $=0.283$, and ensemble retention index $=0.451$ ), in our phylogenetic analysis, with the strict consensus cladogram shown in Fig. 13. The resulting topology is overall very similar to that obtained by Aguirre-Fernández \& Fordyce (2014:fig. 8), with the notable difference that the relationship of

Pontoporia, Brachydelphis and Pliopontos with other inioids which is unresolved in our analysis, yielding a polytomy for Pontoporiidae (sensu Geisler et al., 2012). Our results also resolved a clade (Pan-Inia) of taxa more related to Inia than Pontoporia, which consists of: Meherrinia, Ischyrorhynchus and Isthminia, the latter which is sister to Inia. Although Bremer support values for most of these nodes is low (i.e., 1 step), there is stronger support (i.e., 2 steps) for the clade that includes Ischyrorhynchus + Isthminia+Inia. The new position of Ischyrorhynchus is likely a result of our rescoring of several characters based on observations of the type and additional specimens of Ischyrorhynchus. This position differs from all previous phylogenetic analyses (e.g., Geisler et al., 2012; Aguirre-Fernández \& Fordyce, 2014) but it is consistent with Cozzuol (2010)'s proposal for a subfamily grouping of Ischyrorhynchinae within Iniidae (Cozzuol, 1996). Our analysis did not include Saurocetes spp., a large Pan-Inia known from the late Miocene age Ituzaingó Formation of Argentina and Solimões Formation of Brazil, and represented mainly by fragmentary mandibular remains (Cozzuol, 1996; Cozzuol, 2010). We also did not include Goniodelphis hudsoni from the Mio-Pliocene age Bone Valley Formation of Florida (Allen, 
801 1941), which is represented by a poorly preserved cranium with some similarities to

802 Ischyrorhynchus. Both taxa require reexamination that remains outside the scope of this study.

803

804 Our results differ in resolving a clade grouping Lipotes, Platanista and the fossil lipotid

805 Parapontoporia spp., which shares some similarities with Platanistoidea sensu Simpson (1945)

806 and Geisler \& Sanders (2003). The recovery of Platanista in a close relationship with other

807 Lipotes has previously been recovered in the exclusively morphological analyses of Geisler \&

808 Sanders (2003) and Aguirre-Fernández \& Fordyce (2014), whereas exclusively molecular and

809 combined molecular and morphological analyses consistently recover Platanista as a separate,

810 basal branching clade from Lipotes and Inioidea, likely reflecting long branch attraction (see

811 Geisler et al., 2011:figs. 1-2, and references therein). Regardless, both morphological and

812 molecular (and combined) analyses have consistently recovered Inioidea as a clade (i.e., Inia and

813 Pontoporia), a finding replicated by our own results, herein.

814

815 Discussion

816 1. Isthminia compared with other living and extinct inioids

817 Among inioids, the general morphology of Isthminia in dorsal view most resembles the known

818 elements of Meherrinia and Inia, although the broad circular outline of the maxillae and their

819 contact with the vertex is also reminscient of Brachydelphis. In ventral view, Isthminia is most

820 similar to Ischyrorhynchus and Goniodelphis, although both of these taxa are represented by

821 more fragmentary remains than Isthminia. The rostrum of Isthminia is robust, with dorsal fusion

822 between the right and left premaxillae, and possessing relatively robust upper and lower

823 dentition, with strong wear on the apical crowns, although Isthminia does not exhibit lingual 


\section{PeerJ Reviewing Manuscript}

824 cusps in the posterior dentition observed in Inia. Additionally, tooth counts are more similar to

825 Inia, certainly more so than Pontoporia. The strong groove separating the premaxilla and maxilla

826 along the length of the rostrum is most similar to Inia, whereas Pontoporia and Ischyrorhynchus

827 show a small but deep indentation that runs the length of the rostrum. In some ways, the rostrum

828 of Isthminia is reminiscent of Kampholophos serrulus Rensberger, 1969, from the late Miocene

829 of California, which has dentition that is far more crenulated than Isthminia. In several basic

830 traits (e.g., robust dentition reduced in number, robust rostrum, and a broad exposure of the

831 temporal fossa), Kampholophos shares many similarities with Pan-Inia, although its

832 phylogenetic position has not been determined beyond potential membership in Delphinida (see

833 Salinas-Márquez et al., 2014).

834

835 Isthminia exhibits a large dorsal infraorbital foramen on the maxilla, which is proportionally

836 similar to Inia and Ischyrorhynchus, although absolutely larger in Isthminia (Figs. 3 and 6). In

837 ventral view, Isthminia shows anteriorly elongate anterior sinus system, invading the maxilla, a

838 feature observed also in Inia (Fraser \& Purves, 1960). Overall, the lateral profile of the rostrum

839 in Isthminia remains in the same level as the cranium, whereas both Pontoporia and Inia shows a

840 slightly dorsal elevation of its orbits, a featured most pronounced among odontocetes in Lipotes.

841 Using the small crest on the supraoccipital as an external demarcation of the hemispherical

842 midline of the underlying dermocranium, we note that the vertex in Isthminia is slightly sinistral

843 (see also Fig. 7), to the same degree as Inia, and more so than Pontoporia, although not as highly

844 sinistral as Lipotes. Interestingly, Isthminia lacks the strongly elevated and knob-like vertex of

845 Inia and Ischyrorhynchus, maintaining a lower vertex profile similar to Meherrinia,

846 Brachydelphis, and Pontoporia, although its frontals do form the absolute apex just as they do in 
847 Inia, with a pedestal that can be directly pinched between an index finger and thumb, anterior of

848 the apex of the supraoccipital shield. Notably, Isthminia lacks the strongly inflated bosses of the

849 premaxillary sac fossae seen in nearly all other inioids (Fig. 5 and 6).

850

851 The mandible of Isthminia is most similar to Inia, in terms of an elongate mandibular symphysis,

852 morphology in transverse section, and general size (Fig. 8 and 9). Both Isthminia and Inia lack

853 the distinct ventrolateral groove in Pontoporia. Mental foramina with overhanging sulci are

854 prominent in Isthminia, but smaller in Inia, although in both they extend posteriorly along the

855 body of the ramus; also, the anterior termination of the mandibles in Isthminia is rounded in

856 lateral view, whereas it is more angular in Inia. In lateral view, the coronoid process in Isthminia

857 is less elevated, relative to the level of the trough in the mandibular symphysis than either Inia or

858 Pontoporia. Both in Isthminia and Inia, the posterior termination of the dentition and the anterior

859 termination of the acoustic window occur in close proximity, whereas in Pontoporia these

860 landmarks are separated by a large gap along the mandibular ramus. Lastly, for the scapula,

861 Isthminia shares the most similarities with Inia, although the scapula is not known in the

862 majority of fossil inioids, and it remains unpublished in the otherwise abundantly represented

863 Brachydelphis mazeasi (e.g., MUSM 887). We note the presence of both a complete scapula and

864 a humerus in the type specimen of Incacetus broggii Colbert, 1944 (AMNH 32656) from marine

865 strata in the Ica Desert (likely the Pisco Formation, although it may derive from older strata) in

866 Peru. Both elements hint at inioid affinities for this taxon, from the Pisco Basin, which has

867 previously been identified as a kentriodontid (Muizon, 1988b).

868

869

\section{Taphonomy, body size, and ecomorphology}


870

871

872

873

874

875

876

877

878

879

880

881

882

883

884

885

886

887

888

889

890

891

892

Isthminia was recovered from the type locality with the ventral surface of the skull exposed

stratigraphic up, at the outcrop surface, directly overlying the mandibles, which were preserved

slightly askew from the main axis of the skull, dorsal surface up (Fig. S1). Careful inspection of the surrounding quarry, prior to excavation, led to the recovery of 3 isolated teeth. The scapula

was recovered within 1 meter of the skull and jaws, mid-way through the excavation. Overall,

the distribution of the skeletal elements at the type locality are similar to other fossil odontocetes

in the same size, in similar depositional environments, and that have been recovered as

associated skeletons (e.g., Tanaka \& Fordyce, 2015). By comparison, there are generally far

fewer postcranial elements preserved with the type specimen of Isthminia than might be

expected, suggesting that most of the skeleton was likely eroded away from overlying rock.

The degree of disarticulation at the type locality corresponds to Articulation Stage 2 described by Pyenson et al. (2014b) in their supplemental files, which matches the same articulation stage in Boessenecker et al. (2014). In terms of bone modification, there is no evidence of bite marks from marine macroscavengers, and we did not observe any of the phosphatization, fragmentation and polish described by Boessenecker et al. (2014) for marine vertebrates from the Mio-Pliocene age Purisima Formation of California. In sum, these observations point to the type specimen of Isthminia representing a single individual skeleton showing little transport, slight disarticulation, and burial in a low energy depositional environment.

Using both the Platanistoidea and Delphinoidea body size equations from Pyenson \& Sponberg (2011), we calculated the total length of Isthminia between $284-287 \mathrm{~cm}$, respectively, based on an estimate of the bizygomatic width of the skull by doubling the distance from the lateral 
893 surface of the zygomatic process to the midpoint of the mesethmoid. Assuming the type

894 specimen represents a mature individual, this total length exceeds the largest values for Inia

895 (LACM 19590 with $\mathrm{TL}=221 \mathrm{~cm}$ ) and Pontoporia $(\mathrm{CAS} 16529$, with $\mathrm{TL}=157 \mathrm{~cm})$ from the

896 adult specimens cited in Pyenson \& Sponberg (2011)'s dataset, although we note that adult Inia

897 and Pontoporia can attain lengths as large as $300 \mathrm{~cm}$ and $175 \mathrm{~cm}$, respectively (Nowak 1999).

898 The reconstruction of Isthminia's TL closely matches medium- to large-sized extant delphinoids, 899 such as Grampus griseus (Cuvier, 1812), which has an average TL of $283 \mathrm{~cm}$, based on 8 adult 900 specimens in Pyenson \& Sponberg (2011)'s dataset. Notably, Isthminia ranks among the largest 901 of inioids, though it was slightly smaller than a similar estimate for Ischyrorhynchus (TL of 288$902291 \mathrm{~cm}$ based on MACN 15135). Saurocetes spp., a Pan-Inia taxon, was likely much larger, but 903 poorly known, based on incomplete material from the Ituzaingó Formation of Argentina for 904 Saurocetes gigas (only known from a proximal fragment of a mandibular symphysis and isolated 905 teeth), and mandibles and partial cranial specimens for S. argentinus from the late Miocene 906 Ituzaingó, Urumaco, and Solimões formations of Argentina, Venezuela, and Brazil, respectively 907 (see Gutstein et al., 2014b).

908

909 We also examined two relevant morphological ecomorphological indices: mandibular bluntness 910 index (MBI) and proportional orbit size. First, we followed methods outlined by Werth (2006)

911 and calculated a MBI value of 0.548 for Isthminia, which is greater than values for either Inia or

912 Pontoporia. By comparison, the MBI value for Isthminia most closely resembles those for other

913 delphinids reported by Werth (2006). We also generated a simple metric to compare relative

914 orbit size (ROS) among odontocetes, in an effort to better quantify the proportionally large orbits

915 of Isthminia, especially with respect to Inia and Pontoporia. Using antorbital notch width to 
916 control for size (following Pyenson \& Sponberg, 2011), we calculated a ROS value for Isthminia

917 at 0.40 (Table 3). This value is larger than Inia, but smaller than Meherrinia, Pontoporia, and

918 Brachydelphis spp. Comparisons among the dimensionless ROS indices do not immediately

919 reveal any strong phylogenetic or ecologic structuring (Table 3), with Isthminia having a ROS in

920 the same range as fossil and living marine odontocetes. It is entirely possible that ROS does not

921 have the same importance in the sensory ecology of odontocetes as it does in other marine

922 mammals that do not echolocate and therefore depend much more on visual prey detection

923 (Schusterman et al., 2000; Debey \& Pyenson, 2013).

924

925 The preponderance of occlusal wear facets on the apices of the lower and upper tooth crowns is

926 not dissimilar from extant delphinioids, such as off-shore specimens of Tursiops, and fossil

927 delphinidans such as Lophocetus pappus. Following Loch \& Simões-Lopes (2013), we scored

$928100 \%$ dental wear in the type and only specimen of Isthminia, with every tooth showing at least

929 superficial apical tooth wear of the dental crown; only 2 out of 41 complete teeth in the dentition

930 of the type specimen showed simultaneous wear in apical and lateral tooth facets. Although the

931 percentage of simultaneous apical and lateral wear ranks comparatively low for Loch \& Simões-

932 Lopes (2013)'s dataset of delphinids from the coast of Brazil, the dominance of superficial dental

933 crown corresponding to Index 1 is generally in line with similar modes from pelagic delphinids

934 in their dataset. We note, however, that Isthminia has different overall tooth morphology and

935 lower tooth counts as compared with stem and crown delphinoids, and fewer teeth than Inia and 936 Pontoporia.

937 
938 Overall, Isthminia shares some ecomorphological similarities with pelagic odontocetes,

939 especially with delphinioids of comparable body sizes and MBI. In comparative studies of

940 congeneric or closely related odontocetes with disparate habitat preferences (e.g., riverine or

941 estuarine versus oceanic settings), Monteiro-Filho et al. (2002) and Galatius et al. (2011)

942 demonstrated associated morphological complexes with each habitat. Pelagic odontocetes, for

943 example, tend to have rostra with less ventral inclination, possess facial regions that were

944 dorsally and posteriorly expansive and more concave in lateral aspects. Isthminia is consistent

945 with this pelagic characterization in having a rostral plane less ventrally inclined than either Inia

946 or Pontoporia, and having a broad exposure of the maxillae posterior of the level of the external

947 nares. Future work should quantify these features more broadly across fossil delphinidans in a

948 way that can be comparable with Galatius et al. (2011)'s findings.

949

\section{3. Environmental and ecological implications}

951 Planktotrophy is the dominant feeding mode of both the benthonic and nektonic fossil

952 invertebrate assemblages preserved in the Piña Facies (Schwarzhans \& Aguilera, 2013; O’Dea et

953 al., 2007) demonstrating high planktonic productivity. In contrast, modern Caribbean shelf

954 shallow waters are dominated by low planktonic but high benthic productivity driven by

955 autotrophic reef and seagrass growth (O’Dea et al., 2007). The shift from planktotrophic to

956 autotrophic benthic communities took place across the Caribbean when the Isthmus of Panama

957 formed $\sim 3.5 \mathrm{Ma}$ (Jackson \& O’Dea, 2013). The presence of Isthminia and other predators

958 including billfishes (Fierstine, 1978; JVJ, pers. obs.), chondrichthyans (Carrillo-Briceño et al.,

959 2015) and cetaceans such as kogiids (Velez-Juarbe et al., 2015), physeteroids (Vigil \& Laurito, 
960 2014), and delphinoids (JVJ, pers. obs.), all with presumably high metabolic rates, corroborate

961 further the presence of high planktonic productivity in the Piña Facies.

962

963 The source of high planktonic productivity is not yet resolved. Upwelled, nutrient-rich Pacific

964 waters may have entered the Caribbean coast of Panama (O'Dea et al., 2012) through the

965 remaining straits of the Central American Seaway (Jackson \& O’Dea, 2013; Coates \& Stallard,

966 2013; Leigh et al., 2014) in the late Miocene. High rates of cloning in cupuladriid bryozoans

967 (O’Dea \& Jackson, 2009), high variations in stable isotopes along skeletal profiles from

968 gastropod shells (Robbins et al., 2012), and high variations in temperature-mediated zooid sizes

969 (O’Dea et al., 2007) all suggest that strong seasonal upwelling was a dominate regime in this

970 area. Alternatively, nutrients may have originated from more localized terrestrial runoff, as

971 proposed for emergent platforms in present-day Colombia (Montes et al., 2015). However,

972 reconciling the small watershed of the Isthmus of Panama with the geographic and stratigraphic

973 extent of the Piña Facies (approximately 40-50 m thick) make it unlikely that high productivity

974 levels observed throughout the facies could have been maintained solely from terrestrial input,

975 even if higher rainfall and greater orogenic or volcanic activity in the late Miocene resulted in

976 increased nutrient input from the proto-Isthmus. As such, it is unlikely that there were large

977 rivers close to the area, further corroborating the hypothesis that Isthminia lived in a fully marine

978 habitat.

979

980 The high abundance of benthic foraminifera assemblages with modern or ancient upper and

981 middle bathyal depth ranges led Collins et al. (1996) to conclude that the Piña Facies of the

982 Chagres Formation was deposited in deeper waters. Collins et al. (1996) suggested that the Piña 
983 Facies were preserved as the Central American Seaway deepened following the deposition of the 984 underlying shallow-water Gatún Formation, and therefore represented the ephemeral formation 985 of a fairly deep oceanic connection from the Pacific Ocean into the Caribbean Sea, prior to final 986 closure of the Isthmus of Panama. This pattern of sediment deepening at the end of the Miocene, 987 followed by shallowing and final closure of the Isthmus in the late Pliocene, repeats itself across 988 several basins along the Isthmus of Panama (Coates et al., 2003; 2004), pointing to pervasive 989 regional eustatic sea level rise at the end of the Miocene (Miller et al., 2005) as a driver.

991 De Gracia et al. (2012) suggested that the extent of deepening at this time was extreme. They 992 used the vast abundance of lanternfish (e.g., Diaphus Eigenmann \& Eigenmann 1890) recovered 993 from the sediments (Schwarzhans \& Aguilera, 2013) as evidence that the Piña Facies was 994 deposited in up to $700 \mathrm{~m}$ of water depth (see Supplemental File 2 for otolith abundance data 995 from this unit, near the type locality). Although lanternfish do inhabit deeper waters during the 996 day to avoid predation, they are well known to migrate into shallow waters at night to feed.

997 Indeed, their otoliths are abundant in shallow water $(<35 \mathrm{~m})$ sediments in Bocas del Toro today. 998 Thus, the presence of lanternfish, even in the great abundance observed in the Piña Facies is 999 insufficient to assume deep-water deposition.

1001 In a more recent study, Hendy et al. (in press) used molluscan, foraminferal, coral, and fish 1002 otolith assemblages, along with detailed sedimentological evidence, to conclude that the 1003 deepening event was considerably less pronounced. They suggested the deposition of the Piña 1004 Facies was around $125 \mathrm{~m}$ in depth, closely reflecting a previous estimate made by Collins et al. 1005 (1999) using corals and fish otoliths. Intense productivity or upwelling characteristic of the Piña 
1006 Facies could have compressed thermoclines and compensation depths resulting in an apparent

1007 compression of the depth ranges of diagnostic taxa resulting in possibly anomalously deep

1008 estimates. The presence of a single specimen of Isthminia sheds little light on this palaeodepth

1009 discussion, except to note that modern day pelagic delphinoids concentrate around the neritic

1010 zone (Benoit-Bird \& Au, 2003; Gowans et al., 2007; Benoit-Bird \& McManus, 2012).

1011

1012

1013 4. The Evolutionary History of Inioidea in the Americas

1014 The fossil record of Inioidea reveals a far broader geographic distribution in the past than would

1015 be predicted from the extant ranges of Inia and Pontoporia. Fossil inioids outside of South

1016 America have predominantly been recovered from marine deposits representing nearshore

1017 depositional environments, although Isthminia's recovery from rocks representing potentially a

1018 open ocean setting is consistent with ecomorphological traits that Isthminia shares with pelagic

1019 odontocetes alive today (Fig. 14). Although some freshwater Pan-Inia lineages from the late

1020 Miocene of Argentina may have been $\sim 4 \mathrm{~m}$ in total length, they are based on fragmentary

1021 remains (Cozzuol, 2010), and Isthminia is the largest marine inioid yet reported, in addition to

1022 being the only fossil inioid known from the Caribbean. Based on the available evidence,

1023 Isthminia occupied a high trophic level in a highly productive fully marine tropical Caribbean

1024 coastal ecosystem that predated the complete formation of the Panamanian Isthmus. Many of the

1025 bony fish species that are recorded in spectacular abundance from adjacent otolith assemblages

1026 in the Chagres Formation (Supplemental File S2) may have formed a dominant portion of the

1027 prey resources for Isthminia, as they do for extant delphinids (see Kelley \& Motani, 2015).

1028 


\section{PeerJ Reviewing Manuscript}

1029 Hamilton et al. (2001) suggested that the marine ancestors of Inia, subsequent to their divergence

1030 from Pontoporia, invaded freshwater ecosystems of Amazonia during eustatic sea-level highs of

1031 the middle Miocene, and evolved freshwater habits prior to the subsequent drop in eustatic sea-

1032 level late in the Neogene. This proposed evolutionary scenario is entirely consistent with the late

1033 Miocene (Messinian) antiquity of Isthminia, which establishes a minimum boundary on its

1034 divergence with Inia (Fig. 15). Fossil remains attributable directly to Inia spp. have been

1035 reported from Pleistocene age freshwater deposits of the Rio Madeira Formation in Brazil

1036 (Cozzuol, 2010). An isolated Pan-Inia humerus from the late Miocene Ituzaingó Formation

1037 implies that this clade had already invaded turbid, obstructed shallow rivers and flooded forests

1038 typical of today's Amazonian freshwater ecosystems by this time, although this humerus may

1039 belong to extinct taxon more closely related to Ischyrorhynchus (Gutstein et al., 2014a).

1040

1041 The results of our phylogenetic analysis, however, cast some complexity on a simple scenario of

1042 marine-to-freshwater directionality given the phylogenetic placement of Ischyrorhynchus, from

1043 freshwater deposits of South America. Taken at face value, our analysis points to either two

1044 separate freshwater invasions in South America from marine ancestry at different times (one for

1045 Ischyrorhynchus, and another for Inia), or a single invasion with the origin at the unnamed clade

1046 of Ischyrorhynchus +Isthminia +Inia, with a marine re-invasion leading to Isthminia (Fig. 15).

1047 While the overwhelming marine ancestry for Inioidea is clear from the phylogenetic background

1048 of most odontocetes, there is no clear parsimonious argument for the directionality of marine-

1049 freshwater ecological transitions. Geisler et al. (2011) discussed such ecological complexity in

1050 considering Hamilton et al. (2001)'s scenario, pointing specifically to separate instances of

1051 overlapping geographic and ecological distributions between sympatric pairs of exclusively 
1052 freshwater and estuarine to marine odontocete taxa: e.g., Sotalia fluviatilis (Gervais, 1853) with

1053 Sotalia guianensis (Van Beneden, 1864), both delphinids, in South America (Cunha et al., 2005;

1054 Caballero et al., 2007; Gutstein et al., 2014b); and, prior to the former's extinction, Lipotes

1055 vexillifer and Neophocaena phocoenoides (Cuvier, 1829), a phocoenid, in China. These extant

1056 examples, along with the recent fossil discoveries of putatively marine odontocetes in freshwater

1057 depositional environments (Bianucci et al., 2013; Boessenecker \& Poust, 2015) suggest that

1058 freshwater invasions by marine odontocetes have happened frequently throughout the Neogene,

1059 in different continental margins, across major lineages, and, as our results suggest, perhaps

1060 within clades as well.

1061

1062 For South America, we conclude that marine odontocetes likely invaded freshwater ecosystems several times, with platanistids representing an initial invasion in the middle Miocene that

1064 ultimately disappeared, prior or subsequent to later a singular or repeated inioid invasions in the

1065 late Miocene. Future work, including new discoveries, will hopefully increase branch support for

1066 the phylogenetic arrangement of Pan-Inia (and basal inioids), and better refine this scenario for

1067 South American inioid evolution, and elsewhere. These evolutionary hypotheses may also be

1068 compared with diversification and selective extinction patterns for other vertebrate groups that

1069 invaded Amazonian freshwater ecosystems from marine ancestries (e.g., stingrays belonging to

1070 Potamotrygonidae Garman 1877, see Lovejoy et al., 1998; croakers in the genus Plagioscion

1071 Gill, 1861, see Cooke et al., 2012), in conjunction with the timing of orogenetic events during

1072 the late Neogene (Hoorn et al., 2010). Lastly, comparative phylogenetic analyses of the

1073 physiology and functional morphology of odontocetes, and other possible marine tetrapod 
1074 analogs that have overlapping ecological occupancy will also provide a better basis for

1075 evaluating adaptational hypotheses that explain their evolution (Kelley \& Pyenson, 2015).

1076

1077

1078 


\section{Supplemental Information}

1080 Supplemental Figure S1. Collecting the type specimen of Isthminia at the type locality on 18 1081 June 2011. A) The specimen exposed in the outcrop, at low tide, with the scapula, oriented 1082 lateral side facing stratigraphic up, approximately $35 \mathrm{~cm}$ away from the skull, which was 1083 exposed ventral side up. Scale bar $=10 \mathrm{~cm}$. Photo: J. Velez-Juarbe. B) With the high tide 1084 returning, removal of the plaster jacketed sediment block, containing the skull, exposed the 1085 mandibles located directly underneath it. The dorsal or occlusal surface of the mandible was 1086 oriented facing stratigraphic up. Photo: A. O’Dea.

1087

1088 Supplemental File S1. Character matrix for this study, modified from Aguirre-Fernández \& 1089 Fordyce (2014), with coding for Isthminia panamensis and an updated the character scoring for 1090 Ischyrorhynchus.

1091

1092 Supplemental File S2. Otolith data collected by Orangel Aguilera from the Chagres Formation. 1093

1094 Supplemental Video S1. CT movie though the skull Isthminia panamensis, using a stack of 1997 1095 DICOM images, processed in ImageJ (v. 1.48), oriented dorsal to image top, right lateral to the 1096 image right, and left lateral to image left. Original CT data are available at Smithsonian X 3D 1097 (http://3d.si.edu) and at Zenodo (DOI: 10.5281/zenodo.27214). 1098 1099

\section{Additional Information and Declarations}




\section{Data Deposition}

1102 The following information was supplied regarding the deposition of related data: full resolution

1103 3D models and original CT data are available online at Smithsonian X 3D (http://3d.si.edu) and 1104 archived, along with supplemental data, in Zenodo, (https://zenodo.org/record/27214) at the 1105 following DOI: $10.5281 /$ zenodo.27214.

1106

\section{New Species Registration}

1108 The electronic version of this article in Portable Document Format (PDF) will represent a 1109 published work according to the International Commission on Zoological Nomenclature (ICZN),

1110 and hence the new names contained in the electronic version are effectively published under that

1111 Code from the electronic edition alone. This published work and the nomenclatural acts it

1112 contains have been registered in ZooBank, the online registration system for the ICZN. The

1113 ZooBank LSIDs (Life Science Identifiers) can be resolved and the associated information viewed

1114 through any standard web browser by appending the LSID to the prefix "http://zoobank.org/".

1115 The LSID for this publication is: urn:lsid:zoobank.org:pub:4763A625-883D-4263-B376-

1116 33B9F9AD56A4. The online version of this work is archived and available from the following 1117 digital repositories: PeerJ, PubMed Central and CLOCKSS.

1118

1119 Anatomical Abbreviations

1120 adif, anterior dorsal infraorbital foramen

1121 alis, alisphenoid 
1122 ap, angular process of mandible

1123 C, canine tooth

1124 cp, coronoid process of mandible

1125 cuneif, cuneiform

1126 dsss, dorsal sagittal sinus sulcus

1127 fplpts, fossa for the postorbital lobe of the pterygoid sinus

1128 fr, frontal

1129 gf, glenoid fossa of squamosal

1130 I, incisor tooth or teeth

1131 ju, jugal

1132 la, lacrimal

1133 Ma, mega-annum, period of 1 million years

$1134 \max$, maxilla

1135 mc, maxillary crest

1136 me, mesethmoid

1137 mef, mental foramen or foramina

1138 mf, mandibular foramen

1139 ms, mandibular symphysis

1140 na, nasal

1141 nar, bony narial opening or naris

1142 nuc, nuchal crest

1143 pa, parietal

1144 PC, postcanine tooth or teeth 
1145 pdif, posterior dorsal infraorbital foramen

1146 pls, posterolateral sulcus of the premaxilla

1147 pmax, premaxilla

1148 pmaxf, premaxillary foramen

1149 pms, posteromedial sulcus of the premaxilla

1150 pmsf, premaxillary sac fossa

1151 popf, postorbital process of the frontal

1152 propf, preorbital process of the frontal

1153 scap, scaphoid

1154 socc, supraoccipital

1155 sopf, supraorbital process of frontal

1156 smf, suprameatal fossa

1157 sq, squamosal

1158 tc, temporal crest of the frontal

1159 trap, trapezoid

1160 uncif, unciform

1161 vom, vomer

1162 zpsq, zygomatic process of squamosal

1163

\section{Institutional Abbreviations}

1165 AMNH, Divisions of Paleontology and Vertebrate Zoology, American Museum of Natural 1166 History, New York, New York, U.S.A. 
1167 CAS, Department of Ornithology and Mammalogy, California Academy of Sciences, San

1168 Francisco, California, U.S.A

1169 CMM, Calvert Marine Museum, Solomons, Maryland, U.S.A.

1170 IRSNB, Institut royal des Sciences naturelles de Belgique, Brussels, Belgium.

1171 LACM, Departments of Mammalogy and Vertebrate Paleontology, Natural History Museum of 1172 Los Angeles County, Los Angeles, California, U.S.A

1173 MACN, Museo Argentino de Ciencias Naturales "Bernardino Rivadavia," Buenos Aires, 1174 Argentina.

1175 MLP, Museo de La Plata, La Plata, Argentina.

1176 MNHN, Muséum national d'Histoire naturelle, Paris, France.

1177 MUSM, Museo de Historia Natural, Universidad Nacional Mayor San Marcos, Lima, Peru.

1178 UCMP, University of California Museum of Paleontology, Berkeley, California, U.S.A.

1179 UF, Florida Museum of Natural History, Gainesville, Florida, U.S.A.

1180 USNM, Departments of Paleobiology and Vertebrate Zoology (Division of Mammals), National 1181 Museum of Natural History, Smithsonian Institution, Washington, D.C., U.S.A.

1182

1183 Acknowledgements

1184 Foremostly, we thank Felix Rodriguez, Owen McMillan and Eldredge Bermingham for their 1185 support. We would also like to thank Celideth DeLeon for her circumspect administrative help.

1186 We are grateful to the Government of Panama's Ministerio de Comercio e Industrias (MICI) and 1187 staff at STRI for assistance, including Santosh Jagadeeshan, Andrew Ugan and Carlos De 1188 Gracia, for logistical support with collecting and transporting the type specimen of Isthminia, 1189 which was collected and exported with permits from the MICI. We thank Steven Jabo and Peter 
1190 Kroehler (USNM) for technical assistance with preparation of the type specimen. We also thank

1191 Tomas Hrbek, an anonymous reviewer, and Academic Editor Mark Young for helpful comments

1192 on the manuscript. For insightful discussions and access to unpublished data, we thank Stephen

1193 J. Godfrey, Olivier Lambert, Mizuki Murakami, R. Ewan Fordyce, James G. Mead, Charles W.

1194 Potter, David J. Bohaska, and Alexander J. Werth. We also thank James F. Parham for

1195 suggestions and comments on many drafts of the manuscript. We also thank Charles W. Potter,

1196 John J. Ososky, and James G. Mead (all USNM), Stephen J. Godfrey (CMM), Rodolfo S.

1197 Gismondi (MUSM), Christine Argot, Guillaume Billet, and Christian de Muizon (all MNHN),

1198 Patricia A. Holroyd (UCMP), Marcelo Ruguero (MLP), Alejandro Kramarz (MACN), and John

1199 Flynn, Ruth O’Leary, Nancy B. Simmons, and Neil Duncan (all AMNH), and staff at the

1200 Instituto de Desenvolvimento Sustentável Mamirauá in Tefé, Brazil, who all provided access to

1201 collections under their care. We are grateful for the support of the NMNH Imaging, including the

1202 late Donald Hurlbert, James Di Loreto, Brittany Hance, and Kristen N. Quarles, for photography

1203 of the type specimen of Isthminia. We thank Tatjana Dzambazova (Autodesk), Antonije

1204 Velevski and Ralph Wiedemeier for website assistance with the 3D model of Isthminia, and

1205 Günter Waibel, Adam Metallo, Vincent Rossi, and Jon Blundell of the Smithsonian's

1206 Digitization Program Office for their support with 3D digitization. We are grateful to Esteban

1207 Pacheco for printing and donating a 3D model of Isthminia. We also thank Tina Tennessen for

1208 her timely editorial skills, and the input of Lauren O'Regan and Loretta Cooper (all at USNM).

1209 Orangel Aguilera kindly gave permission to use his fish otolith data from the Chagres Formation.

1210 Marcelo Viana and Orangel Aguilera kindly allowed us to use fish images in preliminary drafts

1211 of Isthminia's reconstruction. We are indebted to the generosity and expertise of Laurel Collins,

1212 for help with the stratigraphy and age of the Chagres Formation, and we thank Austin Hendy for 
1213 the base map in Figure 1. Lastly, we thank Julia Molnar for her creative and careful execution on

1214 the life reconstructions of Isthminia.

1215

1216 References

1217

1218 Abel O. 1905. Les Odontocètes du Boldérien (Miocène supérieur) des environs d'Anvers.

1219 Mémoires du Musée royal d'Histoire naturelle de Belgique 3: 1-155

1220

1221 Aguirre-Fernández G, Fordyce RE. 2014. Papahu taitapu, gen. et sp. nov., an early Miocene

1222 stem odontocete (Cetacea) from New Zealand. Journal of Vertebrate Paleontology 34:195-210.

1223

1224 Allen GM. 1921. A new fossil cetacean. Bulletin of the Museum of Comparative Zoology 65:1122514.

1226

1227 Allen GM. 1941. A fossil river dolphin from Florida. Bulletin of the Museum of Comparative

1228 Zoology 89:1-24.

1229

1230 Ameghino F. 1891. Caracteres diagnosticos de cincuenta especies nuevas de mamiferos fosiles

1231 argentinos. Revista Argentina de Historia Natural 1:129-167

1232

1233 Arnason U, Gullberg A, Janke A. 2004. Mitogenomic analyses provide new insights into

1234 cetacean origin and evolution. Gene 333:27-34.

1235 
1236 Barnes LG. 1984. Fossil odontocetes (Mammalia: Cetacea) from the Almejas Formation, Isla

1237 Cedros, Mexico. PaleoBios 42:1-46.

1238

1239 Barnes LG. 1985a. Fossil pontoporiid dolphins (Mammalia: Cetacea) from the Pacific coast of 1240 North America. Contributions in Science 363:1-34.

1241

1242 Barnes LG. 1985b. The late Miocene dolphin Pithanodelphis Abel, 1905 (Cetacea:

1243 Kentriodontidae) from California. Contributions in Science 367:1-27.

longirostris) over a range of spatial and temporal scales. Behavioral Ecology and

Benoit-Bird KJ, Au WW. 2003. Prey dynamics affect foraging by a pelagic predator (Stenella Sociobiology 53:364-373.

1248

Benoit-Bird KJ, McManus MA. 2012. Bottom-up regulation of a pelagic community through spatial aggregations. Biology Letters 8:813-816.

1251

Basin. Journal of Vertebrate Paleontology 33: 741-745.

1255

1256 Blainville, HMD de. 1817. Les quadrupèdes, les cétacés et les animaux fossiles in Nouveau

1257 dictionnaire d'histoire naturelle, appliquée aux arts, à l'agriculture, à l'économie rurale et 
1258 domestique, à la médecine, etc. par une societé de naturalistes et d'agriculteurs (Desmarest AG, 1259 ed). Déterville, Paris, France 9:1-624.

1260

1261 Boessenecker RW, Perry FA, Schmitt JG. 2014. Comparative taphonomy, taphofacies, and

1262 bonebeds of the Mio-Pliocene Purisima Formation, central California: Strong physical control on 1263 marine vertebrate preservation in shallow marine settings. PloS ONE 9:e91419.

1264

1265 Boessenecker RW, Poust AW. 2015. Freshwater occurrence of the extinct dolphin

1266 Parapontoporia (Cetacea: Lipotidae) from the upper Pliocene nonmarine Tulare Formation of

1267 California. Palaeontology 58:489-496.

1268

1269

Bolli HM. 1957. Planktonic foraminifera from the Oligocene-Miocene Cipero and Lengua

1270 formations of Trinidad, B.W.I. Bulletin of the United States National Museum 215:97-123.

1271

1272

Bolli HM, Bermúdez PJ. 1965. Zonation based on planktonic foraminifera of middle Miocene to

1273 Pliocene warm-water sediments. Boletín Informative Asociación Venezolana de Geología

1274 Mineraría y Petróleo 8:119-149.

1275

Brisson MJ. 1762. Regnum animale in Classes IX distributum, sive synopsis methodica sistens generalem animalium distributionem in Classes IX, et duarum primarum Classium,

1278 Quadrupedum scilicet \& Cetaceorum, particulare divisionem in Ordines, Sectiones, Genera, et 1279 Species. T. Haak: Paris, 296 pp. 
1281 Burmeister G. 1871. On Saurocetes argentinus a new type of Zeuglodontidae. Annals and 1282 Magazine of Natural History 6:51-55

1283

1284 Burmeister G. 1885. Examen critico de los mamiferos y reptiles fosiles denominados por D.

1285 Augusto Bravard y mencionados en su obra precedente. Annales del Museo Nacional de Buenos 1286 Aires 3:93-174.

1287

1288

1289

1290

1291 guianensis) dolphins. Marine Mammal Science 23:358-386.

1292

1293

Cantino PD, de Queiroz K. 2014. PhyloCode: A Phylogenetic Code of Biological Nomenclature 1294 (Version 4c). Ohio University. Available online: http://www.ohiou.edu/phylocode.

1295

1296

1297

1298

1299

1300

Cassens I, Vicario S, Waddell VG, Balchowsky H, Van Belle D, Ding W, Fan C, Lal Mohan RS, 1301 Simões-Lopes PC, Bastida R, Meyer A, Stanhope MJ, Milinkovitch MC. 2000. Independent 1302 1303 adaptation to riverine habitats allowed survival of ancient cetacean lineages. Proceedings of the National Academy of Sciences 97:11343-11347. 
1305 Chapman F, Parr WJ, Collins AC. 1934. Tertiary foraminifers of Victoria, Australia: the

1306 Balcombian deposits of Port Philip (Pt. III). Journal of the Linnenan Society of London 38:5531307577.

1308

1309 Coates AG, Aubry MP, Berggren WA, Collins LS, Kunk M. 2003. Early Neogene history of the 1310 Central American arc from Bocas del Toro, western Panama. Geological Society of America 1311 Bulletin 115:271-287.

1312

1313 Coates AG, Collins LS, Aubry MP, Berggren WA. 2004. The geology of the Darien, Panama, 1314 and the late Miocene-Pliocene collision of the Panama arc with northwestern South 1315 America. Geological Society of America Bulletin 116:1327-1344.

1316

1317 Coates AG, Stallard RF. 2013. How old is the Isthmus of Panama? Bulletin of Marine 1318 Science 89:801-813.

Cohen KM, Finney SC, Gibbard PL, Fan JX. 2013. The ICS international chronostratigraphic 1321 chart. Episodes 36:199-204.

1323 Colbert EH. 1944. A new fossil whale from the Miocene of Peru. Bulletin of the American 1324 Museum of Natural History 83:199-216. 
1326 Collins LS, Coates AG, Berggren WA, Aubry MP, Zhang J. 1996. The late Miocene Panama

1327 isthmian strait. Geology 24:687-690.

1328

1329 Collins LS, Aguilera O, Borne PF, Cairns SD. 1999. A paleoenvironmental analysis of the

1330 Neogene of Caribbean Panama and Costa Rica using several Phyla. Un análisis paleoambiental 1331 del Neogeno del Caribe de Panamá y Costa Rica utilizando varios Phyla. Bulletins of American 1332 Paleontology 357:81-87.

1333

1334 Committee on Taxonomy. 2014. List of marine mammal species and subspecies. Society for 1335 Marine Mammalogy, www.marinemammalscience.org, consulted on 10 July 2015.

1336

1337 Cooke GM, Chao NL, Beheregaray LB. 2012. Marine incursions, cryptic species and ecological 1338 diversification in Amazonia: the biogeographic history of the croaker genus Plagioscion 1339 (Sciaenidae). Journal of Biogeography 39:724-738.

1341 Cooper LN, Berta A, Dawson SD, Reidenberg, JS. 2007. Evolution of hyperphalangy and digit 1342 reduction in the cetacean manus. The Anatomical Record 290:654-672.

1344 Cozzuol MA. 1989. Una nueva especie de Saurodelphis Burmeiter, 1891 (Cetácea: Iniidae) del 1345 "Mesopotamiense" (Mioceno Tardio-Plioceno Temprano) de la provincia de Entre Rios, 1346 Argentina. Ameghiniana 25:39-45. 
1348 Cozzuol MA. 1996. The records of the aquatic mammals in Southern South America. Munchner

1349 Geowissenschaftliche Abhandlungen 30:321-342.

1350

1351 Cozzuol MA. 2010. Fossil record and the evolutionary history of Inioidea. In: Ruiz-Garcia M, 1352 Shostell JM, eds. Biology, Evolution and Conservation of River Dolphins within South America 1353 and Asia. Hauppage: Nova Science Publishers:193-221.

1354

1355 Cunha HA, da Silva VMF, Lailson-Brito J, Santos MC de O, Flores PAC, Martin AR, Azevedo 1356 AF, Fragoso ABL, Zanelatto RC, Sole-Cava AM. 2005. Riverine and marine ecotypes of Sotalia 1357 dolphins are different species. Marine Biology 148:449-457.

1358

1359

Cuvier G. 1812. Rapport fait à la classe des Sciences mathématiques et physiques, sur divers

1360

Cétacés pris sur les côtes de France, pricipalement sur ceux qui sont échoués près de Paimpol, le 1361 7 janvier 1812. Annales du Muséum d'Histoire naturelle 19:13-14.

1362

1363 Cuvier G. 1829. Le règne animal distribué d'après son organisation, pour servir de base à 1364 l'histoire naturelle des animaux et d'introduction à l'anatomie comparée. Paris: Chez Déterville 1365 Tom. 1:291.

1366

1367 Debey LB, Pyenson ND. 2013. Osteological correlates and phylogenetic analysis of deep diving 1368 in living and extinct pinnipeds: What good are big eyes? Marine Mammal Science 29:48-83. 
1370 De Gracia C, Carrillo-Briceño J, Schwarzhans W, Jaramillo C. 2012. An exceptional marine

1371 fossil fish assemblage reveals a highly productive deep-water environment in the Central

1372 American Seaway during the late Miocene. Geological Society of America Abstracts with

1373 Programs 44:164.

1374

1375 d'Orbigny A. 1834. Notice sur un nouveau genre de cétacé des rivières du centre de l'Amérique 1376 méridionale. Nouveau Annales du Musée d'Histoire Naturel de Paris 3:28-36.

1377

1378 Eigenmann CH, Eigenmann RS. 1890. Additions to the fauna of San Diego. Proceedings of the 1379 California Academy of Sciences (Series 2) 3:1-24.

1380

1381 Fierstine HL. 1978. A new marlin, Makaira panamensis from the Late Miocene of Panama. 1382 Copeia 1978:1-11.

1383

1384 Flower WH. 1867. Description of the skeleton of Inia geoffrensis and of the skull of Pontoporia 1385 blainvillii, with remarks on the systematic position on these animals in the order Cetacea.

1386 Transactions of the Zoological Society of London 6:87-116.

1387

1388 Fordyce RE. 2002. Simocetus rayi (Odontoceti: Simocetidae, New Family): a bizarre new 1389 archaic Oligocene dolphin from the eastern North Pacific. Smithsonian Contributions to 1390 Paleobiology 93:185-222. 
1392 Fordyce RE. 2009. Cetacean fossil record. In: Perrin WF, Würsig B, Thewissen, JGM, eds.

1393 Encyclopedia of Marine Mammals, second edition. Amsterdam: Elsevier, 207-215.

1394

1395 Fraser FC, Purves PE. 1960. Hearing in cetaceans. Evolution of the accessory air sacs and the

1396 structure and function of the outer and middle ear in recent cetaceans. Bulletin of the British

1397 Museum of Natural History, Zoology 7:1-140.

1398

1399 Galatius A, Berta A, Frandsen MS, Goodal RNP. 2011. Interspecific variation of ontogeny and

1400 skull shape among porpoises (Phocoenidae). Journal of Morphology 272:136-148

1401

1402 Garman SW. 1877. On the pelvis and external sexual organs of Selachians, with especial 1403 reference to the new genera Potamotrygon and Disceus. Proceedings of the Boston Society of

1404 Natural History 19:197-215

1405

1406 Geisler JH, Sanders AE. 2003. Morphological evidence for the phylogeny of Cetacea. Journal of 1407 Mammalian Evolution 10:23-129.

1408

1409 Geisler JH, McGowen MR, Yang G, Gatesy J. 2011. A supermatrix analysis of genomic, 1410 morphological, and paleontological data from crown Cetacea. BMC Evolutionary Biology $1411 \quad 11: 112$.

1412 
1413 Geisler JH, Godfrey SJ, Lambert O. 2012. A new genus and species of late Miocene inioid 1414 (Cetacea, Odontoceti) from the Meherrin River, North Carolina, U.S.A. Journal of Vertebrate 1415 Paleontology 32:198-211.

1416

1417 Gervais P. 1853. Sur les mammiféres marins qui fréquentent les côtes de la France et plus 1418 particulierement sur une novelle espéce de dauphins propre a la Méditerranés. Bulletin Sociéte 1419 Centrale d'Agriculture et des Comices Agricoles du Département de l'Herault, 40me année, 1420 Montpelier 140-155.

1421

1422 Gervais P. 1855. Histoire Naturelle des Mammifères avec l'indication de leurs moeurs et de 1423 leurs rapports avec les arts le commerce et l'agriculture. Paris: L. Curmer, 1-344. 1424

1425 Gervais P, d'Orbigny A. 1844. Mammalogie. Extraits des procès-verbaux des séances (Société 1426 philomathique de Paris). Séance de 27 avril 1844:38-40.

1428 Gibson ML, Geisler JH. 2009. A new Pliocene dolphin (Cetacea: Pontoporiidae), from the Lee 1429 Creek Mine, North Carolina. Journal of Vertebrate Paleontology 29:966-971. 1430

1431 Gill T. 1861. Synopsis of the subfamily of Percinae. Proceedings of the Academy of Natural 1432 Sciences Philadelphia 1861: 44-52.

1433 
1434 Godfrey SJ, Barnes LG. 2008. A new genus and species of late Miocene pontoporiid dolphin 1435 (Cetacea: Odontoceti) from the St. Marys Formation in Maryland. Journal of Vertebrate 1436 Paleontology 28:520-528.

1437

1438 Gowans S, Würsig B, Karczmarski L. 2007. The social structure and strategies of delphinids: 1439 predictions based on an ecological framework.Advances in Marine Biology, 53, 195-294.

1440

1441 Gray JE. 1846. On the cetaceous animals. In: Richardson J, Gray JE, eds, The Zoology of the 1442 Voyage of H. M. S. Erebus and Terror, under the Command of Capt. Sir J. C. Ross, R. N., F. R. 1443 S., During the Years 1839 to 1843 . London: E. W. Janson, 13-53.

1444

1445 Gingerich PD. 2005. Cetacea. In: Rose KD, Archibald JD, eds. Placental mammals: origin, 1446 timing, and relationships of the major extant clades. Baltimore: Johns Hopkins University Press, $1447 \quad 234-252$.

1448

1449 Gutstein CS, Cozzuol MA, Vargas AO, Suárez M, Schultz CL. 2009. Patterns of skull variation 1450 of Brachydelphis (Cetacea, Odontoceti, Pontoporiidae) from South-Easthern Pacific Neogene. 1451 Journal of Mammalogy 90:504-519.

1452

1453 Gutstein CS, Figueroa-Bravo CP, Pyenson ND, Yury-Yañez RE, Cozzuol MA, Canals M. $2014 \mathrm{a}$. 1454 High frequency echolocation, ear morphology, and the marine-freshwater transition: A 1455 comparative study of extant and extinct toothed whales. Palaeogeography, Palaeoclimatology, 1456 Palaeoecology 400:62-74. 
1458 Gutstein CS, Cozzuol MA, Pyenson ND. 2014b. The antiquity of riverine adaptations in Iniidae

1459 (Cetacea, Odontoceti) documented by a humerus from the late Miocene of the Ituzaingó

1460 Formation, Argentina. The Anatomical Record 297:1096-1102.

1461

1462 Gutstein CS, Horwitz FE, Valenzuela-Toro AM, Figueroa-Bravo CP. 2015. Cetáceos fósiles de 1463 Chile: context evolutivo y paleobiogeográfico. Publicación Ocasional del Museo Nacional de 1464 Historia Natural, Chile 63:339-387.

1465

1466 Hamilton H, Caballero S, Collins AG, Brownell RL. 2001. Evolution of river

1467 dolphins. Proceedings of the Royal Society of London B: Biological Sciences 268:549-556.

1468

1469

Hendy AJW, Jones D, De Gracia D, Velez-Juarbe J. In press. Paleoecology of the Chagres

1470

Formation (latest Miocene) of Panama: reinterpreting the paleoenvironment of a vertebrate-rich

1471 marine fauna. Journal of Geology.

1472

1473

Hoorn C, Wesselingh FP, Steege H, Bermudez MA, Mora A, Sevink J, Sanmartín I, Sanchez1474 Meseguer A, Anderson CL, Figueiredo JP, Jaramillo J, Riff D, Negri FR, Hooghiemstra H, 1475 Lundberg J, Stadler T, Särkinen T, Antonelli A. 2010. Amazonia through time: Andean uplift, 1476 climate change, landscape evolution, and biodiversity. Science 330:927-931.

Hrbek T, da Silva VMF, Dutra N, Gravena W, Martin AR, Farias IP. 2014. A new species of 1479 river dolphin from Brazil or: How little do we know our biodiversity. PLoS ONE 9:e83623. 
1481 IUCN (International Union for Conservation of Nature) 2013. Inia geoffrensis. The IUCN Red

1482 List of Threatened Species. Version 2014.

1483

1484 Jackson JBC, O'Dea A. 2013. Timing of the oceanographic and biological isolation of the

1485 Caribbean sea from the tropical eastern Pacific Ocean. Bulletin of Marine Science 89: 779-800.

1486

1487 Joyce WG, Parham JF, Gauthier J. 2004. Developing a protocol for the conversion of rank-based 1488 taxon names to phylogenetically defined clade names, as exemplified by turtles. Journal of 1489 Paleontology 78:989-1013.

1490

1491 Kelley NP, Motani R. 2015. Trophic convergence drives morphological convergence in marine 1492 tetrapods. Biology Letters 11.1: 20140709.

1493

1494 Kelley NP, Pyenson ND. 2015. Evolutionary innovation and ecology in marine tetrapods from 1495 the Triassic to the Anthropocene. Science 348:aaa3716.

1496

1497 Kellogg R. 1927. Kentriodon pernix, a Miocene porpoise from Maryland. Proceedings of the 1498 United States National Museum 69:1-14

1499

1500 Kellogg R. 1955. Three Miocene porpoises from the Calvert Cliffs, Maryland. Proceedings of 1501 the United States National Museum 105:101-154 
1503 Kellogg R. 1966. A new odontocete from the Calvert Miocene of Maryland. Proceedings of the

1504 United States National Museum 247:99-101

1505

1506 Lambert O, Post, K. 2005. First European pontoporiid dolphins (Mammalia: Cetacea,

1507 Odontoceti) from the Miocene of Belgium and The Netherlands. Deinsea 11:7-20.

1508

1509 Lambert O, de Muizon C. 2013. A new long-snouted species of the Miocene pontoporiid dolphin

1510 Brachydelphis and a review of the Mio-Pliocene marine mammal levels in the Sacaco Basin,

1511 Peru. Journal of Vertebrate Paleontology 33:709-721.

1512

1513 Lebeck, HJ. 1801. Delphinus gangeticus beschrieben von Heinrich Julius Lebeck zu Trankenbar.

1514 Der Gesellschaft naturforschender Freunde zu Berlin Neue Schriften 3: 280-282, Tab. II.

1515

1516 Leigh EG, O’Dea A, Vermeij GJ. 2014. Historical biogeography of the Isthmus of Panama.

1517 Biological Reviews 89:148-72.

1518

1519 Lilljeborg W. 1861. Supplément au mémoire sur les genres Liriope et Peltogaster, H.

1520 Rathke. Nova Acta Regiae Societatis Scientiarum Upsaliensis, Seriei Tertiae. 3:74-102.

1521

1522 Loch C, Simões-Lopes PC. 2013. Dental wear in dolphins (Cetacea: Delphinidae) from southern 1523 Brazil. Archives of Oral Biology 58:134-141.

1524 
1525 Lovejoy NR, Bermingham E, Martin AP. 1998. Marine incursion into South America. Nature 1526 396: 421-422.

1527

1528 May-Collado LJ, Agnarsson I. 2006. Cytochrome b and Bayesian inference of whale phylogeny. 1529 Molecular Phylogenetics and Evolution 38:344-354.

1530

1531 Mead JG, Fordyce RE. 2009. The therian skull: a lexicon with emphasis on the 1532 odontocetes. Smithsonian Contributions to Zoology 627:1-248.

1533

1534 Messenger SL, McGuire JA. 1998. Morphology, molecules, and the phylogenetics of cetaceans. 1535 Systematic Biology 47:90-124.

1536

Miller GS, Jr. 1918. A new river dolphin from China. Smithsonian Miscellaneous Collections 68:1-12.

1539

Miller KG, Kominz MA, Browning JV, Wright JD, Mountain GS, Katz ME, Sugarman PJ,

1541 Cramer BS, Christie-Blick N, Pekar SF. 2005. The Phanerozoic record of global sea-level

1542 change. Science 310:1293-1298.

1543

1544 Monteiro-Filho EL, Monteiro LR, Reis SF. 2002. Skull shape and size divergence in dolphins of 1545 the genus Sotalia: a tridimensional morphometric analysis. Journal of Mammalogy 83:125-134. 1546 
1547 Montes C, Cardona A, Jaramillo C, Pardo A, Silva JC, Valencia V, Ayala C, Pérez-Angel LC,

1548 Rodriguez-Parra LA, Ramirez V, Niño H. 2015. Middle Miocene closure of the Central

1549 American Seaway. Science 348: 226-229.

1550

1551 Morgan GS. 1994. Miocene and Pliocene marine mammal faunas from the Bone Valley

1552 Formation of Central Florida. In Berta A, Deméré TA, eds. Contributions in Marine Mammal

1553 Paleontology Honoring Frank C. Whitmore, Jr. Proceedings of the San Diego Society of Natural

1554 History 29:239-268.

1555

1556

1557

Muizon C de. 1983. Pliopontos littoralis un nouveau Platanistidae Cetacea du Pliocéne de la côte peruvienne. Comptes Rendus de l'Academie des Sciences Paris Série II 296:1101-1104

1558

1559

Muizon C de. 1984. Les vertébré fossiles de la Formation Pisco (Pérou) Deuxiéme partie: les 1560

Odontocétes (Cetacea, Mammalia) du Pliocéne inerieur de Sud Sacaco. Travaux de l'Institut

1561

Français d'Étudies Andines 27:1-188.

1562

1563

Muizon C de. 1988a. Les relations phylogenétiques des Delphinida (Cetacea, Mammalia).

1564 Annales de Paleontologie 74:159-227.

1565

1566 Muizon C de. 1988b. Vertebrés fossiles de la Formation Pisco (Pérou) Troisiéme partie: Les

1567 Odontocètes (Cetacea: Mammalia) du Miocène. Travaux de l'Institut Français d'Études Andines 1568 42: 1-244. 
1570 Murakami M, Shimada C, Hikida Y, Soeda Y, Hirano H. 2014. Eodelphis kabatensis, a new

1571 name for the oldest true dolphin Stenella kabatensis Horikawa, 1977 (Cetacea, Odontoceti,

1572 Delphinidae), from the upper Miocene of Japan, and the phylogeny and paleobiogeography of

1573 Delphinoidea. Journal of Vertebrate Paleontology 34:491-511.

1574

1575 Nikaido M, Matsuno F, Hamilton H, Brownell RL Jr, Cao Y, Ding W, Zuoyan Z, Shedlock AM,

1576 Fordyce RE, Hasegawa M, Okada N. 2001. Retroposon analysis of major cetacean lineages: the

1577 monophyly of toothed whales and the paraphyly of river dolphins. Proceedings of the National

1578 Academy of Sciences 1998:7384-7389.

1579

Nowak RM. 1999. Walker's Mammals of the World. Baltimore: Johns Hopkins University Press.

1582 O'Dea A, Jackson JB, Fortunato H, Smith JT, D'Croz L, Johnson KG, Todd JA. 2007.

1583 Environmental change preceded Caribbean extinction by 2 million years. Proceedings of the

1584 National Academy of Sciences 104:5501-5506.

1585

O'Dea A, Jackson J. 2009. Environmental change drove macroevolution in cupuladriid bryozoans. Proceedings of the Royal Society B: Biological Sciences 276:3629-3634. 1588

O'Dea A, Hoyos N, Rodríguez F, Degracia B, De Gracia C. 2012. History of upwelling in the Tropical Eastern Pacific and the paleogeography of the Isthmus of Panama. Palaeogeography, Palaeoclimatology, Palaeoecology 348:59-66. 
1593 Perrin, WF. 1975. Variation of spotted and spinner porpoise (genus Stenella) in the eastern

1594 Pacific and Hawaii. Bulletin of the Scripps Institution of Oceanography of the University of

1595 California 21:1-206.

1596

1597 Pilleri G, Gihr M. 1977. Observations on the Bolivian (Inia boliviensis d'Orbigny, 1834) and the 1598 Amazon bufeo (Inia geoffrensis de Blainville, 1817) with description of a new subspecies (Inia 1599 geoffrensis humboldtiana). Investigations on Cetacea 8:11-76.

1600

1601 Pyenson ND, Hoch E. 2007. Tortonian pontoporiid odontocetes from the eastern North Sea. 1602 Journal of Vertebrate Paleontology 27:757-762.

1603

1604 Pyenson ND. 2009. Requiem for Lipotes: An evolutionary perspective on marine mammal 1605 extinction. Marine Mammal Science 25:714-724.

1606

1607 Pyenson ND, Sponberg SN. 2011. Reconstructing body size in extinct crown Cetacea (Neoceti) 1608 using allometry, phylogenetic methods and tests from the fossil record. Journal of Mammalian 1609 Evolution 18:269-288.

1610

1611 Pyenson ND, Kelley NP, Parham JF. 2014a. Marine tetrapod macroevolution: Physical and 1612 biological drivers on $250 \mathrm{Ma}$ of invasions and evolution in ocean ecosystems. Palaeogeography, 1613 Palaeoclimatology, Palaeoecology 400: 1-8.

1614 
1615 Pyenson ND, Gutstein CS, Parham JF, Le Roux JP, Chavarría CC, Little H, Metallo A, Rossi V, 1616 Valenzuela-Toro AM, Velez-Juarbe J, Santelli CM, Rubilar Rogers D, Cozzuol MA, Suárez M. 1617 E. 2014b. Repeated mass strandings of Miocene marine mammals from Atacama Region of 1618 Chile point to sudden death at sea. Proceedings of the Royal Society B: Biological 1619 Sciences 281:20133316.

1620

1621 Rensberger JM. 1969. A new iniid cetacean from the Miocene of California. University of 1622 California Publications in Geological Sciences 82:1-34.

1623

1624 1625

Ruiz-Garcia M, Shostell JM. 2010. Biology, Evolution and Conservation of River Dolphins within South America and Asia. Hauppauge: Nova Science Publishers: 1-504.

1626

1627

1628

1629

1630

1631

1632

1633

1634

1635

1636

1637

Robbins JA, Tao J, Grossman EL, O'Dea A. 2012. Exploring the delayed overturn in Caribbean fauna using gastropod stable-isotope profiles to quantify seasonal upwelling and freshening of coastal waters. Geological Society of America Abstracts with Programs 44: paper No. 58-12.

Salinas-Márquez, Fernando M, Barnes LG, Flores-Trujillo JG, Aranda-Manteca FJ. 2014. Una especie de delfín fósil (Cetacea; Delphinoidea; Kentriodontoidae) del Mioceno Medio de Baja California. Boletín de la Sociedad Geológica Mexicana 66:145-164

Scapino R. 1981. Morphological investigation into functions of the jaw symphysis in carnivorans. Journal of Morphology 167:339-375. 
1638 Schusterman RJ, Kastak D, Levenson DH, Reichmuth CJ, Southall BL. 2000. Why pinnipeds

1639 don't echolocate. The Journal of the Acoustical Society of America 107:2256-2264.

1640

1641 Schwarzhans W, Aguilera O. 2013. Otoliths of the Myctophidae from the Neogene of tropical 1642 America. Palaeo Ichthyologica 13:83-150.

1643

1644 Secchi ER, Ott PH, Danilewicz DS. 2003. Effects of fishing by-catch and conservation status of 1645 the franciscana dolphin, Pontoporia blainvillei. In Gales N, Hindell M, Kirkwood R. (eds)

1646 Marine mammals: fisheries, tourism and management issues. Collingwood, Australia: CSIRO

1647 Publishing, pp. 174-191.

1648

1649 Simpson GG. 1945. The principles of classification, and a classification of mammals. Bulletin of 1650 the American Museum of Natural History 85:1-350.

1651

1652 Steeman ME, Hebsgaard MB, Fordyce RE Ho, SYW, Rabosky DL, Nielsen R, Rahbek C,

1653 Glenner H, Sørensen MV, Willerslev E. 2009. Radiation of extant cetaceans driven by 1654 restructuring of the oceans. Systematic Biology 58:573-585.

1655

1656 Swofford DL. 2002. PAUP* v.40b10. Sinauer Associates, Sunderland.

1657

1658 Tanaka Y, Fordyce RE. 2014. Fossil dolphin Otekaikea marplesi (latest Oligocene, New

1659 Zealand) expands the morphological and taxonomic diversity of Oligocene cetaceans. PLoS ONE $1660 \quad 9: \mathrm{e} 107972$. 
1662 Tanaka Y, Fordyce RE. 2015. A new Oligo-Miocene dolphin from New Zealand: Otekaikea 1663 huata expands diversity of the early Platanistoidea. Palaeontologia Electronica 18.2.23A: 1-71. 1664

1665

1666 1667

1668 1669 1670 1671 1672 1673 1674

1675 1676 1677 1678 1679 1680 1681

1682 Van Beneden, P. 1864. Sur un Dauphin nouveau (Delphinus guianensis) et un Ziphioide rare. 1683 Memoires de l'Academie Royale de Sciences Belgique, Bruxelles 16: 1-21. 
1685 Velez-Juarbe J, Wood AR, De Gracia C, Hendy AJW. 2015. Evolutionary patterns among living 1686 and fossil kogiid sperm whales: evidence from the Neogene of Central America. PLoS ONE 1687 10(5): e0129186.

1688

Vermeij GJ, Dudley R. 2000. Why are there so few evolutionary transitions between aquatic and 1690 terrestrial ecosystems? Biological Journal of the Linnean Society 70:541-554

1691

1692

Vigil DI, Laurito CA. 2014. New fossil remains of an odontoceti (mammalia: Cetacea, 1693 physeteroidea) from the late miocene of Panama, Central America. Revista Geológica de 1694 América Central 50:213-217.

1695

Wade BS, Pearson PN, Berggren WA, Pälike H. 2011. Review and revision of Cenozoic tropical 1697 planktonic foraminiferal biostratigraphy and calibration to the geomagnetic polarity and 1698 astronomical time scale. Earth-Science Reviews 104:111-142

1699

Werth AJ. 2006. Mandibular and dental variation and the evolution of suction feeding in 1701 Odontoceti. Journal of Mammalogy 87:579-588.

Whitmore FC Jr. 1994. Neogene climate change and the emergence of the modern whale fauna 1704 of the North Atlantic Ocean. In Berta A, Deméré TA, eds. Contributions in Marine Mammal Paleontology Honoring Frank C. Whitmore, Jr. Proceedings of the San Diego Society of Natural 1706 History 29:223-228. 
1707

1708 Zhou K, Zhou M, Zhao Z. 1984. First discovery of a Tertiary platanistoid fossil from Asia.

1709 Scientific Reports of the Whales Research Institute, Toyko 35:173-181

1710 


\section{TABLE CAPTIONS}

1712 Table 1. Measurements of holotype skull and mandibles (USNM 546125) of Isthminia

1713 panamensis, in mm (modified after Perrin, 1975 and Tanaka \& Fordyce, 2014). Asterisk

1714 indicates doubling of measurement from one side. Positive sign indicates preserved distance.

1715

1716 Table 2. Measurements of the scapula (USNM 546125) of Isthminia panamensis, in mm

1717 (modified after Perrin, 1975).

1718

1719 Table 3. Relative orbit size (ROS) in Isthminia panamensis, and in other fossil and modern

1720 odontocetes, ranked in increasing value.

1721 
FIGURES CAPTIONS

1724 Figure 1. Global map of living and fossil inioids, projected onto an orthographic globe, centered

1725 on $15^{\circ} \mathrm{N}, 45^{\circ} \mathrm{W}$. Extant distributions of Inia geoffrensis (teal and black waterways) and

1726 Pontoporia blainvillei (dark gray), follow data from the International Union for Conservation of

1727 Nature (2013) and Secchi et al. (2003), respectively. Occurrences for fossil data derive from

1728 location of type localities for each taxon, except for reports for the Northern Europe by Pyenson

1729 \& Hoch (2007), Western South America by Gutstein et al. (2015), and Amazonia and Eastern

1730 South America by Cozzuol (2010). Major fossil localites for enumerated inioids identified at

1731 least to the generic level, are listed alphabetically by region, and represented by teal or blue dots,

1732 for freshwater and marine deposits, respectively. Base map generated by Indiemapper

1733 (http://indiemapper.com)

1734

1735 Figure 2. Geographic and stratigraphic context of Isthminia panamensis. A) Map of Central

1736 America with a yellow star representing the type locality, STRI locality 650009. B) Map of

1737 north-central Panama with the distribution of the Chagres Formation, with type locality of

1738 Isthminia in the vicinity of Piña, along with other fossil vertebrates. C) Chronostratigraphic and

1739 lithostratigraphic relationships of the Chagres Formation (modified from Hendy et al., in press, 1740 and Velez-Juarbe et al., 2015).

1741

1742 Figure 3. Dorsal views of the type skull of Isthminia panamensis (USNM 546125) from A)

1743 photographs and B) orthogonal digital three-dimensional polygon model prepared from CT data,

1744 with lighting and color modifications using the Smithsonian X 3D browser. C) Anterior and D)

1745 posterior views of the type skull of Isthminia panamensis (USNM 546125) from orthogonal 
1746 digital three-dimensional polygon model prepared from CT data. See

1747 http://3d.si.edu/explorer?s=h2mqJ9 (dorsal view), http://3d.si.edu/explorer?s=bA5gJO (posterior

1748 view), and http://3d.si.edu/explorer?s=e1seD5

1749 (anterior view) to measure, modify, or download this model.

1750

1751 Figure 4. Ventral views of the type skull of Isthminia panamensis (USNM 546125) from A)

1752 photographs and B) orthogonal digital three-dimensional polygon model prepared from CT data,

1753 with lighting and color modifications using the Smithsonian X 3D browser. See

1754 http://3d.si.edu/explorer?s=iEpExr to measure, modify, or download this model.

1756 Figure 5. Right lateral views of the type skull of Isthminia panamensis (USNM 546125) from A)

1757 photographs and B) orthogonal digital three-dimensional polygon model prepared from CT data, 1758 with lighting and color modifications using the Smithsonian X 3D browser. See

1759 http://3d.si.edu/explorer?s=jn4ynp to measure, modify, or download this model.

1761 Figure 6. Close up views of the vertex in the type skull of Isthminia panamensis (USNM

1762 546125) from A) photographs and B) orthogonal digital three-dimensional polygon model

1763 prepared from CT data, with lighting and color modifications using the Smithsonian X 3D

1764 browser. See http://3d.si.edu/explorer?s=cGDc1L to measure, modify, or download this model.

1766 Figure 7. Computed tomography (CT) slices through the vertex of Isthminia panamensis (USNM

1767546125 ) across four slightly sub-transverse planes that pass anterior to posterior (A-D). CT slices

1768 A-D represent respective CT slices numbers 20566, 20625, 20655, and 20708, available for 
1769 download on the Smithsonian X 3D browser (http://3d.si.edu). Numbers 1 and 2 denote facial

1770 and endocranial sagittal midlines, respectively, showing the sinistral displacement of the facial

1771 bones typical in many odontocetes (Geisler \& Sanders, 2003; Mead \& Fordyce, 2009).

1772

1773 Figure 8. Dorsal views of the mandibles of Isthminia panamensis (USNM 546125) from A)

1774 photographs and B) orthogonal digital three-dimensional polygon model prepared from CT data, 1775 with lighting and color modifications using the Smithsonian X 3D browser. C) Anterior and D) 1776 posterior views of the mandibles of Isthminia panamensis (USNM 546125) from orthogonal 1777 digital three-dimensional polygon model prepared from CT data. See

1778 http://3d.si.edu/explorer?s=hhl3iu (dorsal view), http://3d.si.edu/explorer?s=cgvhM3 (posterior 1779 view), and http://3d.si.edu/explorer?s=gR4Rhv (anterior view) to measure, modify, or download 1780 this model. Parentheses denote missing structure(s).

1781

1782 Figure 9. Ventral views of the mandibles of Isthminia panamensis (USNM 546125) from A)

1783 photographs and B) orthogonal digital three-dimensional polygon model prepared from CT data, 1784 with lighting and color modifications using the Smithsonian X 3D browser. C) Left lateral and 1785 D) right lateral views of the mandibles of Isthminia panamensis (USNM 546125) from 1786 orthogonal digital three-dimensional polygon model prepared from CT data. See 1787 http://3d.si.edu/explorer?s=cavfn3 (ventral view), http://3d.si.edu/explorer?s=dGTRVj $($ left 1788 lateral), and http://3d.si.edu/explorer?s=cLO5aZ (right lateral) to measure, modify, or download 1789 this model. Parentheses denote missing structure(s).

1790 
1791 Figure 10. The dentition of Isthminia panamensis (USNM 546125) in close view. A-E) upper

1792 dentition including the rostrum (A) and isolated teeth collected near the skull at the outcrop

1793 surface, showing B, an upper left posterior tooth (likely PC $^{3}$ ) and C), an upper left posterior

1794 tooth. F-I), lower dentition including the mandible (F, G), shown in two parts, with overlapping

1795 images over the mandibular symphysis. H-I), an additional isolated left tooth posterior (almost

1796 certainly $\mathrm{PC}_{12}$ ) was collected at the type locality. Dashed lines with arrowheads indicate

1797 alignment for the occlusion of upper and lower dentition.

1798

1799 Figure 11. Right scapula from Isthminia panamensis (USNM 546125) in lateral (A-B), medial

1800 (C-D), and distal (E-F) views. Each respective paired view shows photographs alongside

1801 orthogonal digital three-dimensional polygon model prepared from CT data, with lighting and

1802 color modifications using the Smithsonian X 3D browser. See

1803 http://3d.si.edu/explorer?s=dmsTMl (lateral view), http://3d.si.edu/explorer?s=jPwTGO (medial

1804 view), and http://3d.si.edu/explorer?s=hwGm9I (distal view). Anatomical terminology for the

1805 scapula follows Tanaka \& Fordyce (2015) and Uhen (2004).

1806

1807 Figure 12. A) Complete, intact left pectoral limb of Inia geoffrensis (USNM 395602), showing 1808 all of the individual osteological elements in articulation. Carpal elements belonging to Isthminia 1809 panamensis (USNM 546125) include B) a possible pisiform; and C) a likely unciform, with D) a 1810 close up of the carpal bones in panel A, for comparison.

1811

1812 Figure 13. Phylogenetic analysis of Isthminia and other inioid odontocetes, showing a strict 1813 consensus cladogram resulting from six most parsimonious trees, 95 steps long, with the 
1814 ensemble consistency index equal to 0.283 and the ensemble retention index equal to 0.451 .

1815 Numbers below nodes indicate decay index/bootstrap values; stem-based clades are indicated by 1816 arcs, while open circles denote node-based clades.

1817

1818 Figure 14. Life reconstruction of Isthminia panamensis gen. et sp. nov., feeding on a flatfish, 1819 which would have been abundant in the neritic zone of the late Miocene equatorial seas of 1820 Panama. Art by Julia Molnar.

1821

1822 Figure 15. Time calibrated phylogenetic tree of select Delphinida, pruned from our consensus 1823 cladogram in Figure 13, including Isthminia, with Delphinoidea collapsed. Stratigraphic range 1824 data derives from published accounts for each taxon, including global ranges. Geologic time 1825 scale based on Cohen et al. (2013). Calibration for major nodes depths follow mean divergence 1826 date estimates by McGowen et al. (2009:table 3) for the following clades: a, Delphinida (24.75 1827 Ma); b, Inioidea + Lipotes (22.15 Ma); c, Delphinoidea (18.66 Ma); and Inioidea (in open white 1828 circle, $16.68 \mathrm{Ma}$ ). All minor node depths are graphical heuristics, and not intended to reflect 1829 actual divergence dates. Arc indicates stem-based clade, Pan-Inia. Ecological habitat preference 1830 is based on depositional environment or extant habitat. Abbreviations: Aquitan., Aquitanian; H., 1831 Holocene; Langh., Langhian; Mess., Messinian; P., Piacenzian; Ple., Pleistocene; Plioc., 1832 Pliocene; Serra., Serravallian; Zan., Zanclean. 


\section{Table $\mathbf{1}$ (on next page)}

Tables 1-3

TABLE CAPTIONS Table 1. Measurements of holotype skull and mandibles (USNM 546125) of Isthminia panamensis, in mm (modified after Perrin, 1975 and Tanaka \& Fordyce, 2014). Asterisk indicates doubling of measurement from one side. Positive sign indicates preserved distance. Table 2. Measurements of the scapula (USNM 546125) of Isthminia panamensis, in mm (modified after Perrin, 1975). Table 3. Relative orbit size (ROS) in Isthminia panamensis, and in other fossil and modern odontocetes, ranked in increasing value. 


\begin{tabular}{|c|c|}
\hline Skull & Measurement (mm) \\
\hline Total length from the most anterior point to the posterior most point: & $571+$ \\
\hline Cranial length: & $185+$ \\
\hline Length of rostrum - from tip to line across hindmost limits of antorbital notches: & 381 \\
\hline $\begin{array}{l}\text { Width of rostrum at base - along line across hindmost limits of antorbital } \\
\text { notches: }\end{array}$ & $124 *$ \\
\hline $\begin{array}{l}\text { Width of rostrum at } 60 \mathrm{~mm} \text { anterior to line across hindmost limits of antorbital } \\
\text { notches: }\end{array}$ & $90 *$ \\
\hline Width of rostrum at mid-length: & $36+$ \\
\hline Width of premaxillae at mid-length of rostrum: & $31+$ \\
\hline Width of rostrum at $3 / 4$ length, measured from posterior end: & $50 *$ \\
\hline Greatest width of premaxillae: & $78 *$ \\
\hline $\begin{array}{l}\text { Projection of premaxillae beyond maxillae measured from tip of rostrum to line } \\
\text { across foremost tips of maxillae visible in dorsal view: }\end{array}$ & $85+$ \\
\hline Width of premaxillae at a line across posterior limits of antorbital notches: & $48^{*}$ \\
\hline Maximum width of premaxillae at mid-orbit level: & $52 *$ \\
\hline Preorbital width at level of frontal-lacrimal suture: & $184^{*}$ \\
\hline Postorbital width across apices of postorbital processes: & $232 *$ \\
\hline $\begin{array}{l}\text { Distance from tip of rostrum to external nares (to mesial end of anterior } \\
\text { transverse margin of right naris): }\end{array}$ & $419+$ \\
\hline $\begin{array}{l}\text { Distance from foremost end of junction between nasals to hindmost point of } \\
\text { margin of supraoccipital crest: }\end{array}$ & 68 \\
\hline Greatest width of external nares: & 49 \\
\hline Median length of the nasals: & 58 \\
\hline Maximum length of the right nasal: & 58 \\
\hline Median length of frontals on the vertex: & 25 \\
\hline $\begin{array}{l}\text { Vertical external height of the skull from ventral most braincase to dorsal } \\
\text { extremity of vertex: }\end{array}$ & $150+$ \\
\hline Bizygomatic width: & $262 *$ \\
\hline $\begin{array}{l}\text { Length of upper left tooth row-from hindmost margin of hindmost alveolus to } \\
\text { tip of rostrum: }\end{array}$ & 329 \\
\hline Number of teeth—upper left: & 18 \\
\hline Number of teeth-upper right: & 18 \\
\hline \multicolumn{2}{|l|}{ Mandible } \\
\hline Maximum preserved length of left mandible: & $478+$ \\
\hline Maximum preserved height of left mandible: & $74+$ \\
\hline Number of teeth-lower left: & 17 \\
\hline Number of teeth-lower right: & 18 \\
\hline $\begin{array}{l}\text { Length of the lower tooth row from tip of mandible to posterior margin of } \\
\text { posterior most alveolus: }\end{array}$ & 315 \\
\hline
\end{tabular}


3 Table 2.

4

\begin{tabular}{ll}
\hline Scapula & Measurement (mm) \\
\hline Maximum height of scapula: & $141+$ \\
Height of scapula from posterior margin of glenoid fossa to glenovertebral angle: & 161 \\
\hline Length of coracoid process: & 40 \\
Greatest width of coracoid process: & 23 \\
Greatest width of acromion process: & 26 \\
\hline
\end{tabular}

5

6 
$7 \quad$ Table 3

8

\begin{tabular}{lllrl}
\hline Genus & species & Specimen & ROS & Source \\
\hline Aulophyseter & morricei & LACM 154100, USNM 11230 & 0.20 & This study (average, $\mathrm{n}=2$ ) \\
Orycterocetus & crocodilinus & USNM 22926 & 0.22 & This study \\
Inia & geoffrensis & USNM 23967, 49582, 395415 & 0.24 & This study (average, $\mathrm{n}=3$ ) \\
Lipotes & vexillifer & USNM 218293 & 0.32 & This study \\
Aprixokogia & kelloggi & USNM 187015 & 0.34 & This study \\
Lophocetus & repenningi & USNM 23886 & 0.36 & This study \\
Simocetus & rayi & USNM 356517 & 0.36 & This study \\
Isthminia & panamensis & USNM 546125 & $\mathbf{0 . 4 0}$ & This study \\
Nanokogia & isthmia & UF 280000 & 0.40 & Velez-Juarbe et al., 2015 \\
Xiphiacetus & bossi & USNM 8842, 175381 & 0.42 & This study (average, $\mathrm{n}=2$ ) \\
Delphinodon & dividum & USNM 7278 & 0.46 & This study \\
Kogia & sima & LACM 47142 & 0.55 & This study \\
Meherrinia & isoni & IRSNB M.2013 & 0.56 & Geisler et al., 2012 \\
Pontoporia & blainvillei & USNM 482707, 482717, & 0.57 & This study (average, $\mathrm{n}=3$ ) \\
& & 482771 & & \\
\hline Atocetus & nasalis & LACM 30093 & 0.58 & Barnes, 1985a \\
Kentriodon & pernix & USNM 8060 & 0.58 & This study \\
Parapontoporia & wilsoni & UCMP 83790 & 0.62 & Barnes, 1985b \\
Brachydelphis & jahuayensis & MNHN PPI 267, 268; MUSM & 0.70 & Lambert \& Muizon, 2013 (average, $\mathrm{n}=4$ ) \\
& & 567,568 & 0.80 & Lambert \& Muizon, 2013 (average, $\mathrm{n}=3$ ) \\
Brachydelphis & mazeasi & MNHN PPI 121, 266; MUSM & & \\
\hline & & 564 & & \\
\hline
\end{tabular}

10 
Map of fossil and living Inioidea

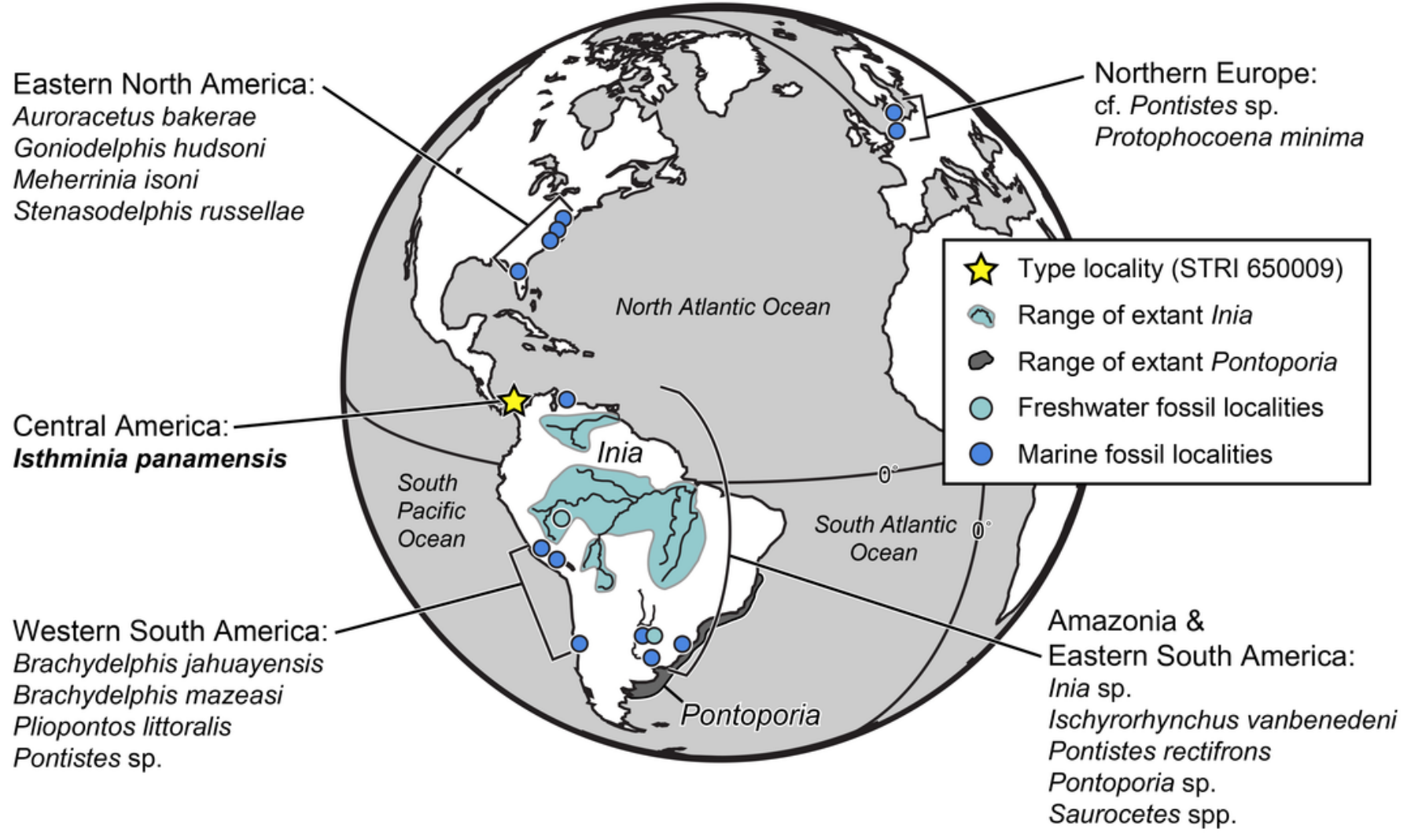




\section{2}

\section{Locality and geology}

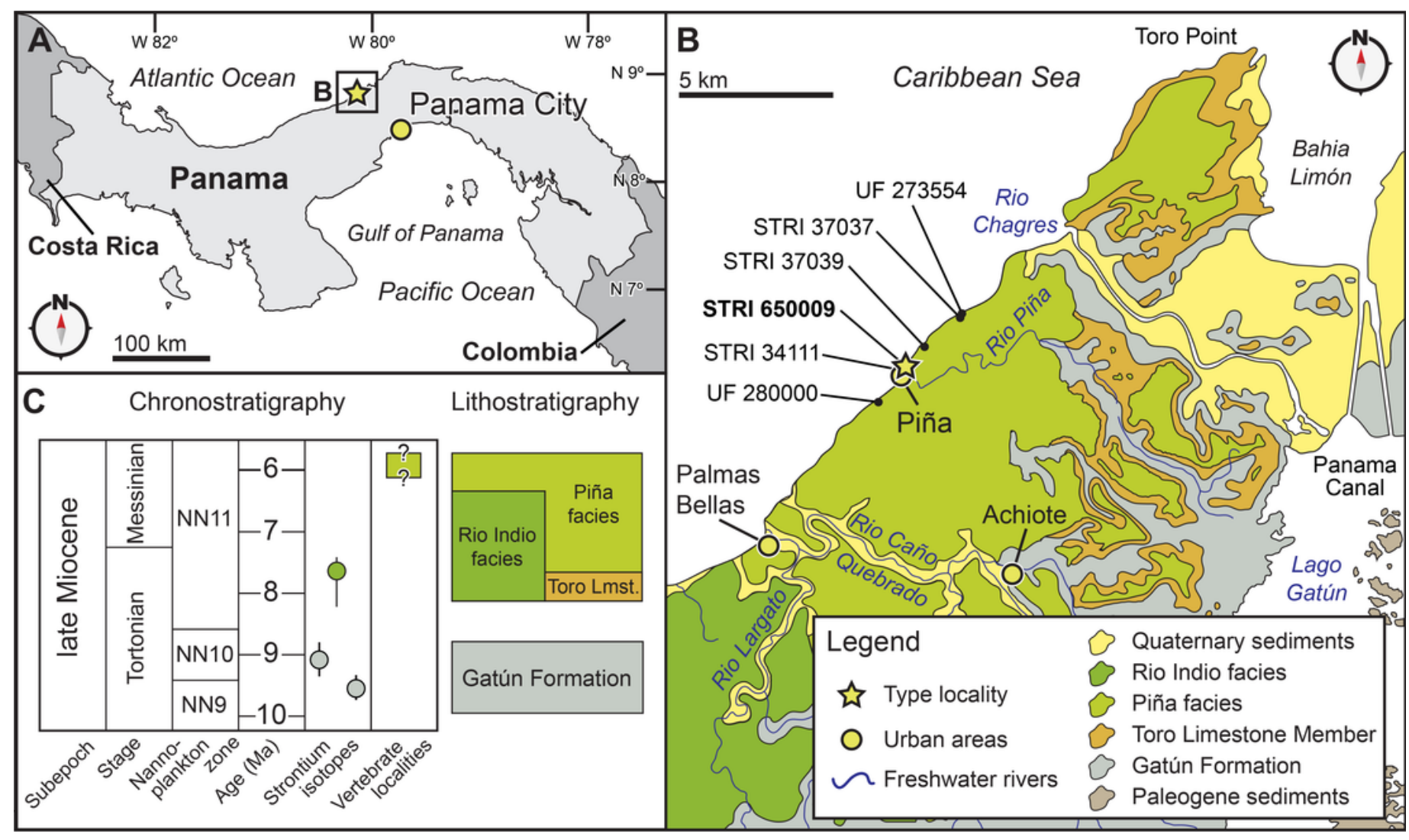


3

Skull in dorsal, anterior, and posterior views

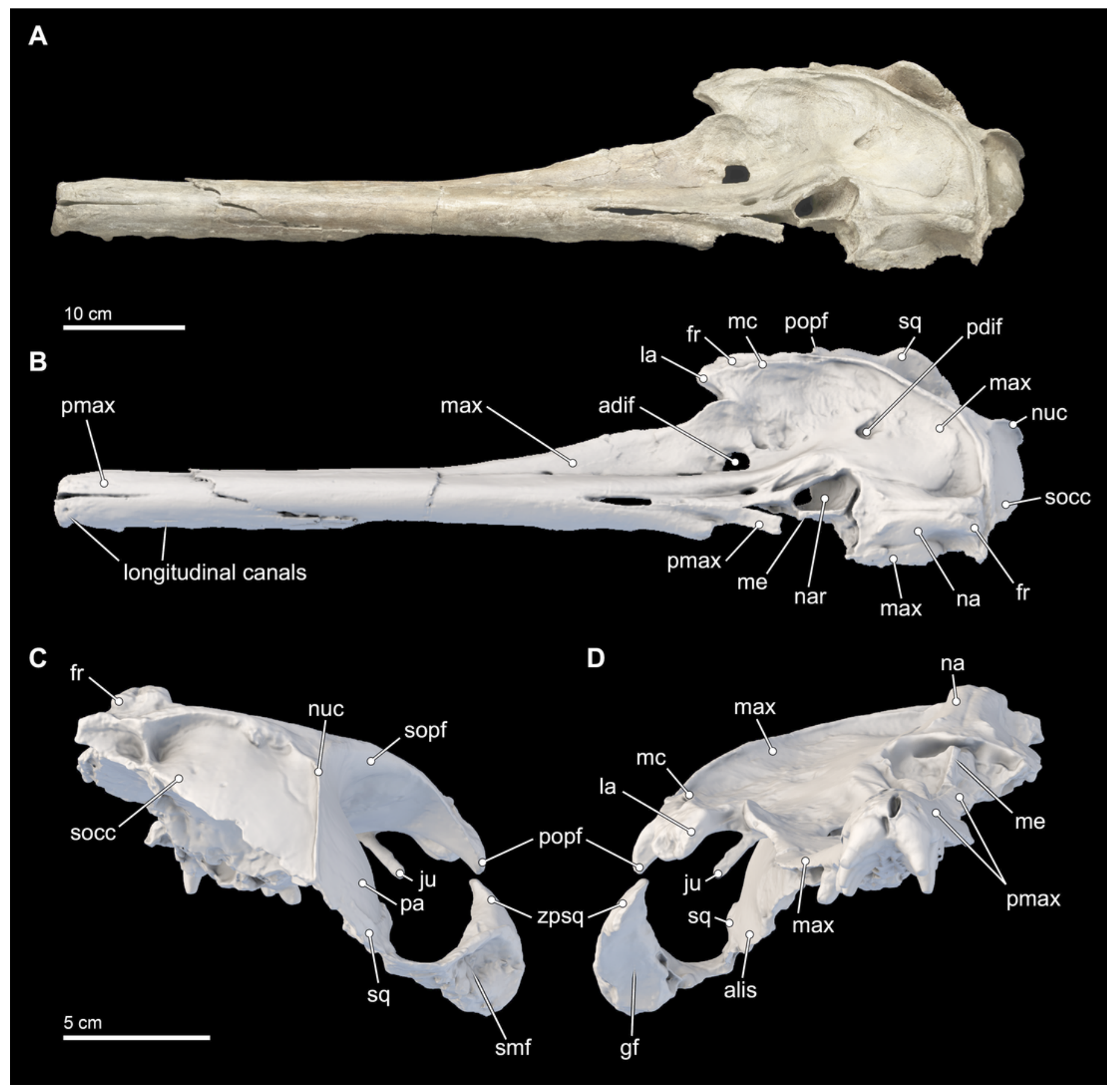


4

Skull in ventral view

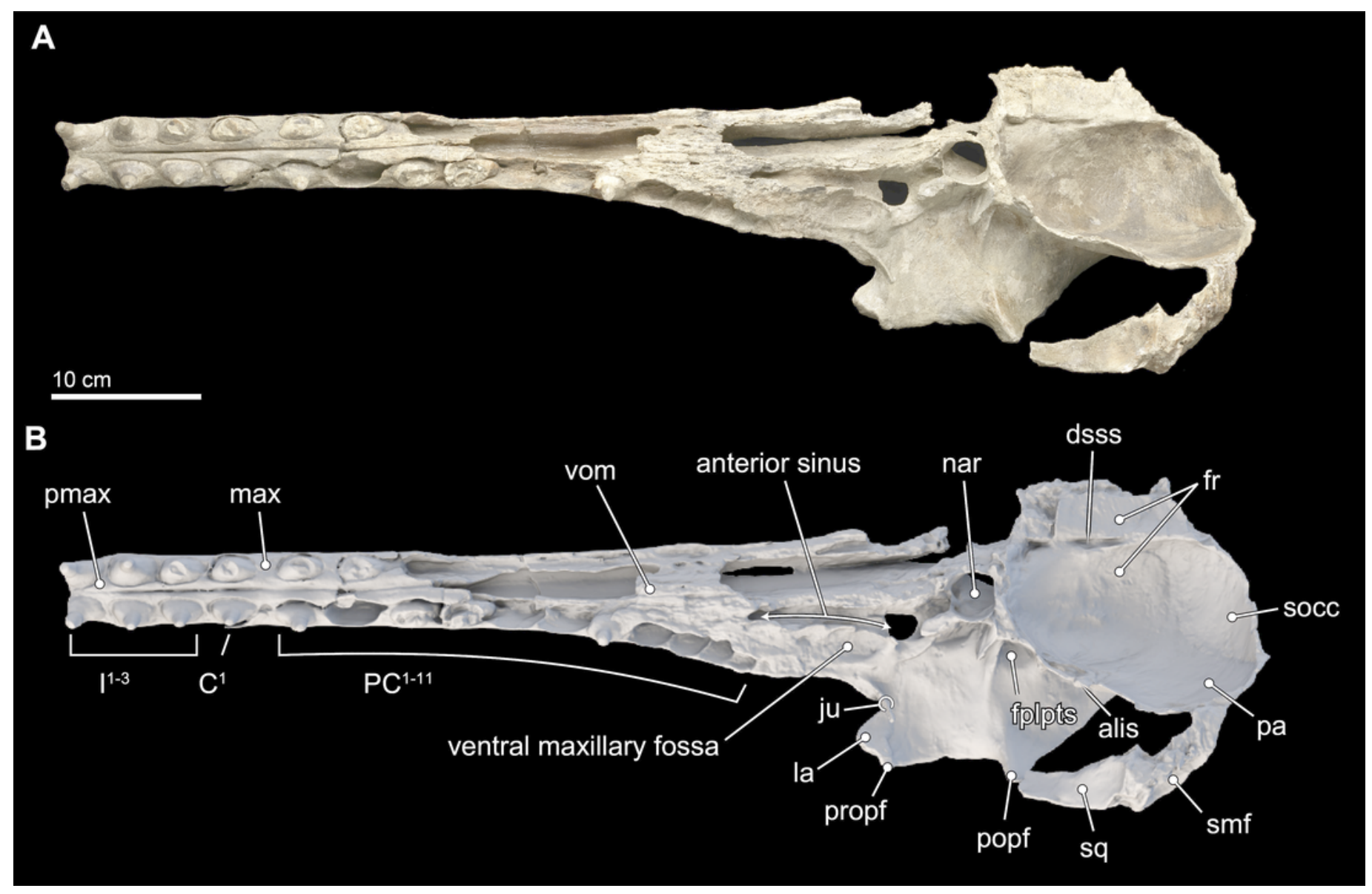




\section{5}

Skull in lateral view

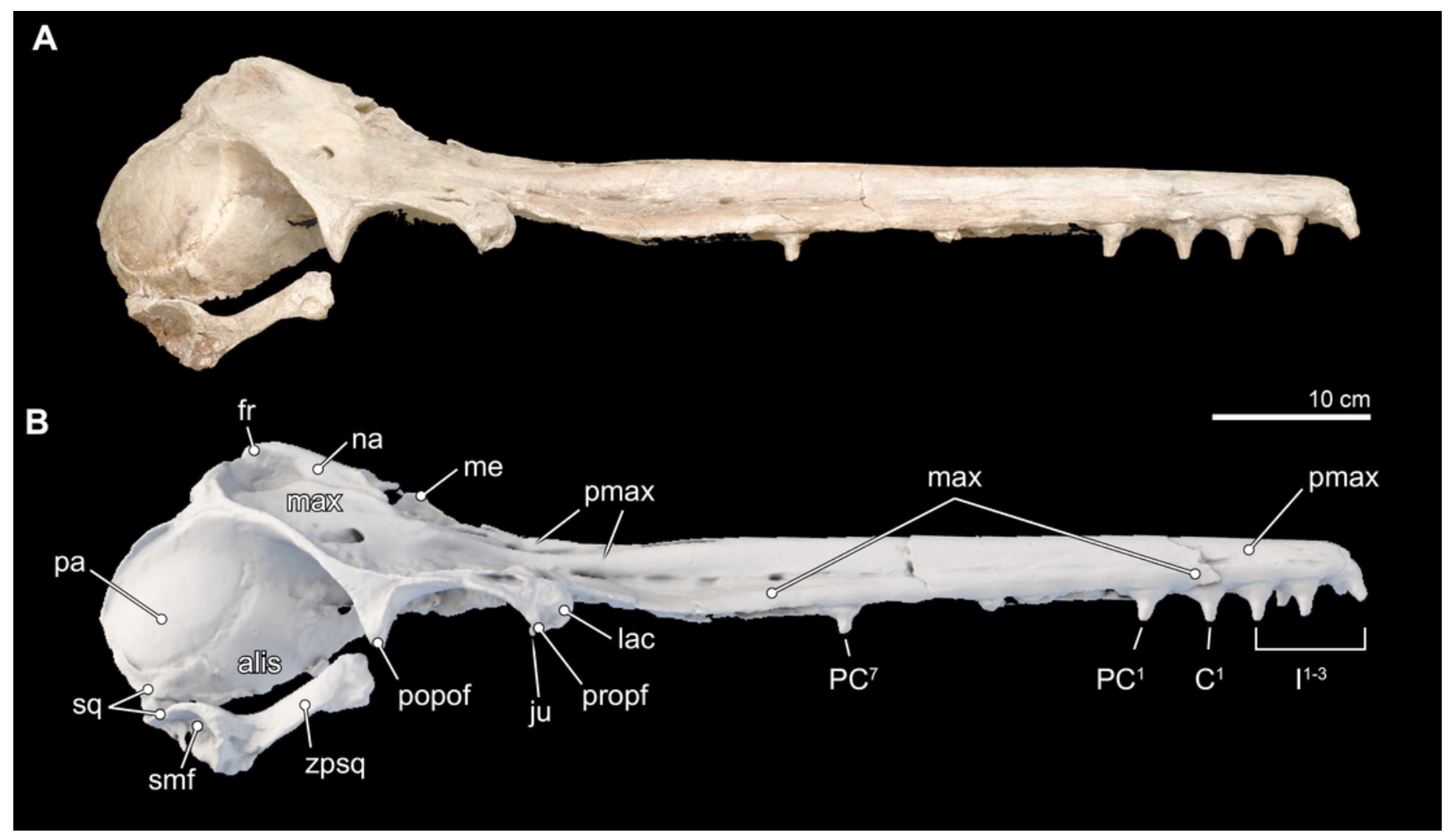


6

Close-up on vertex of skull

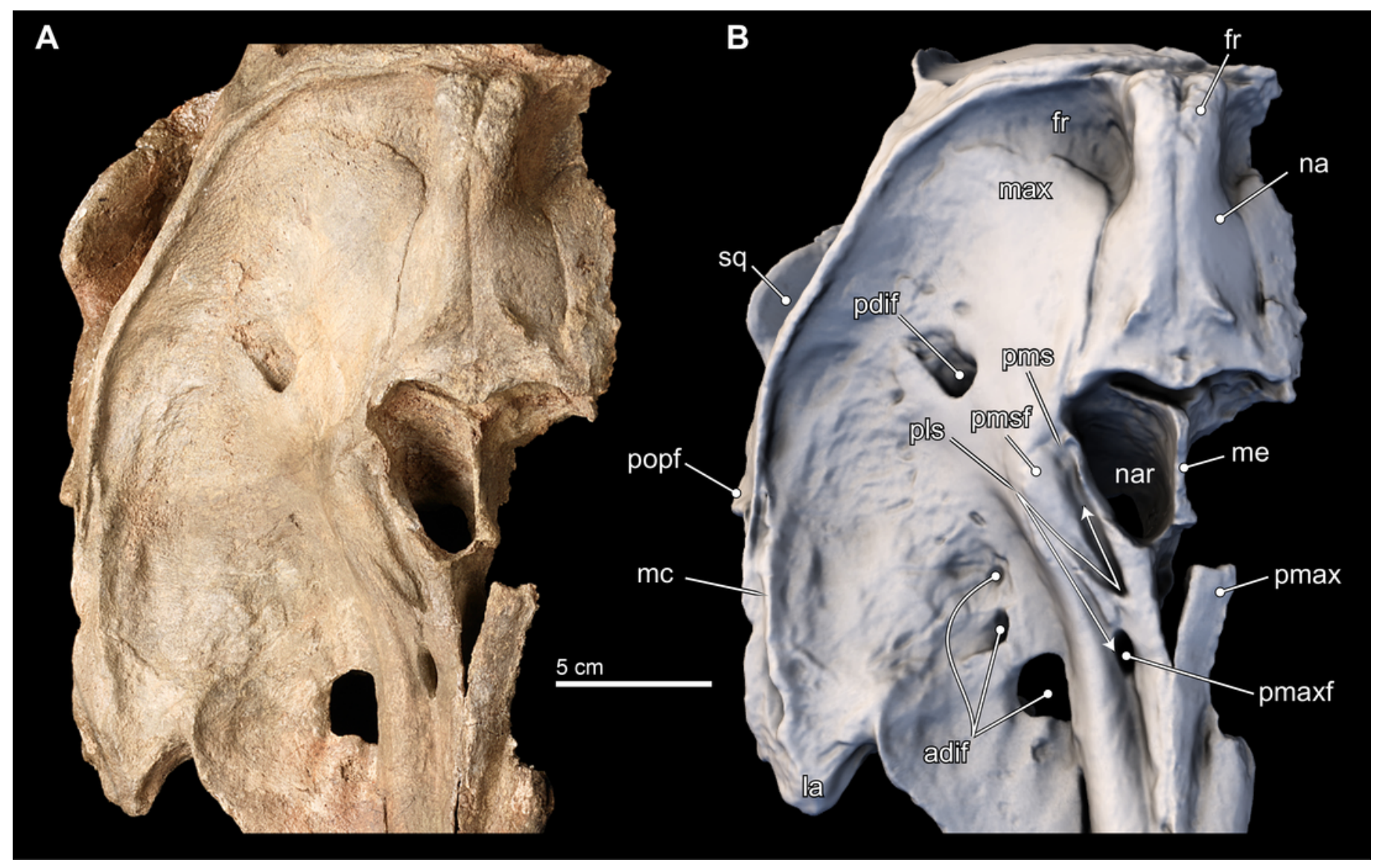




\section{7}

Transverse CT slices through the skull

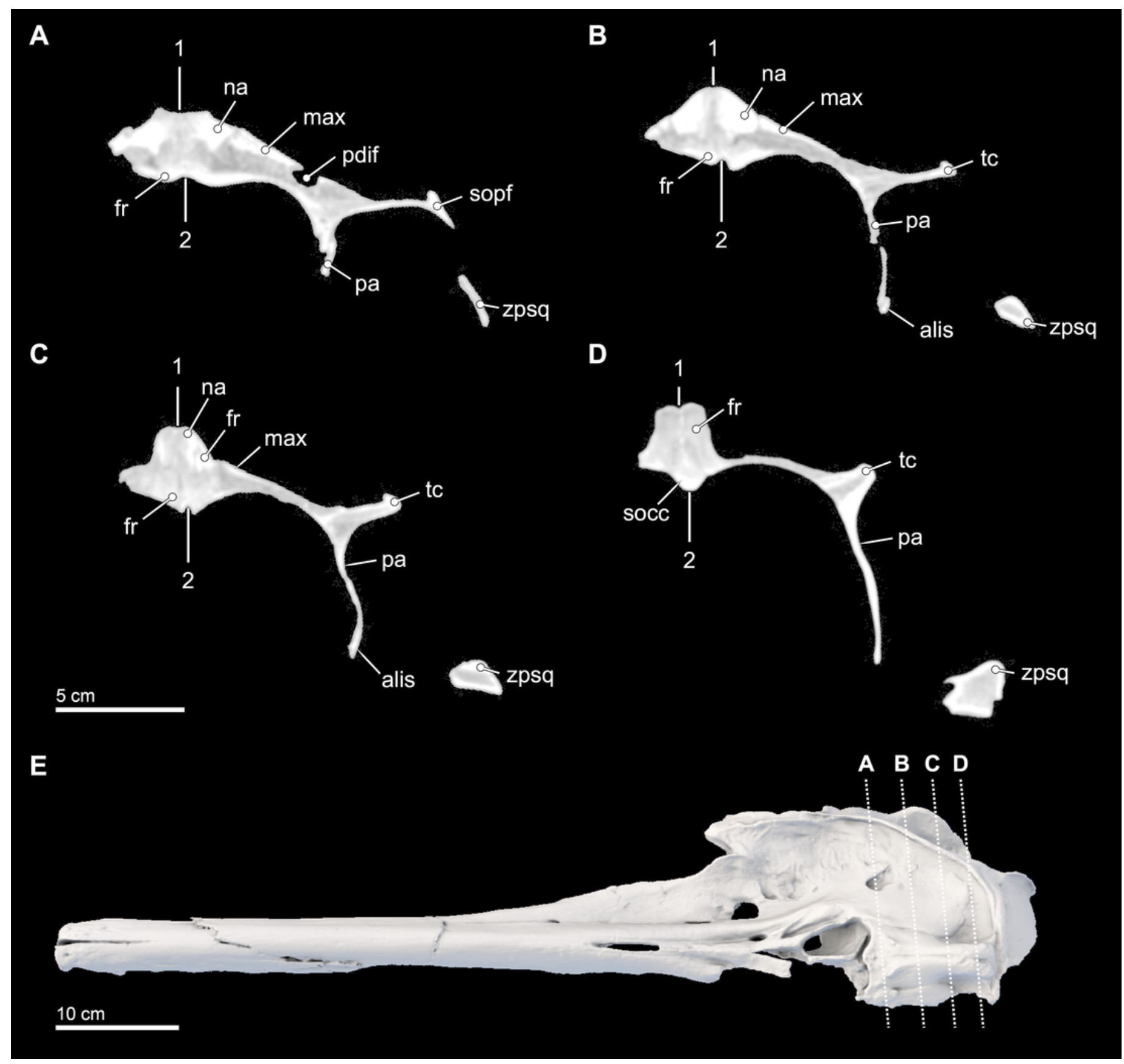


8

Mandibles in dorsal, anterior, and posterior views

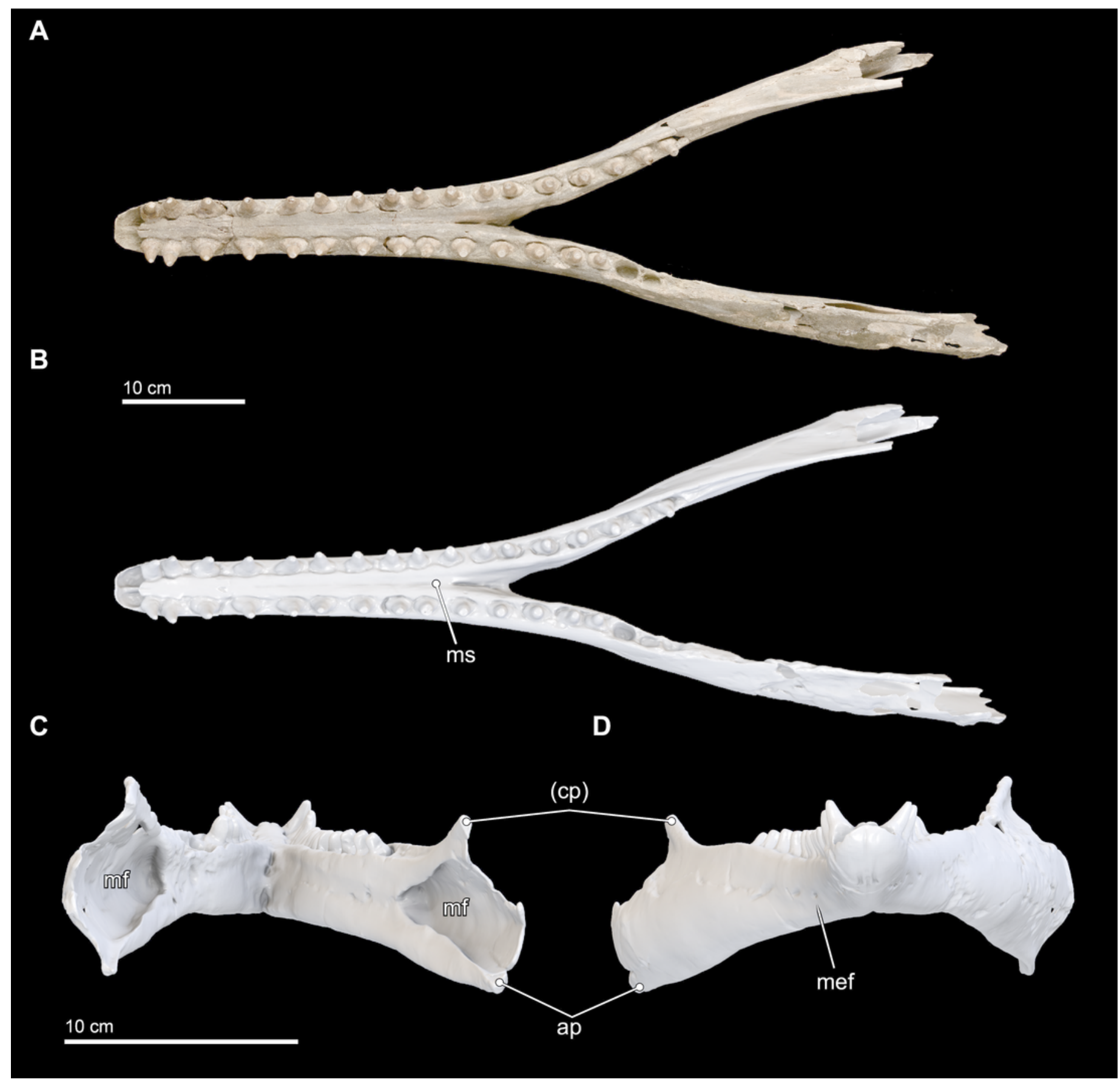


9

Mandibles in ventral and lateral views

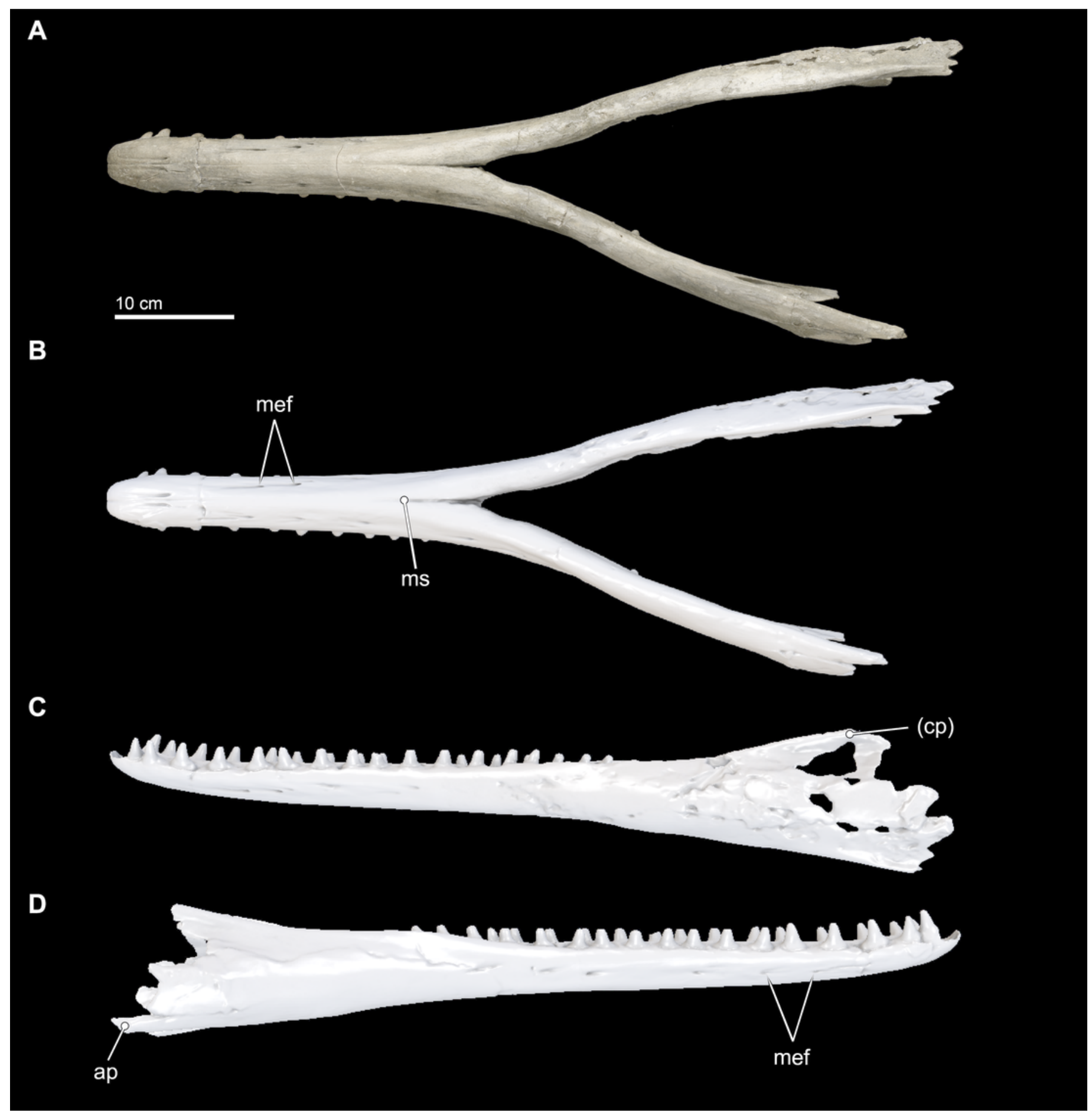


Close-up of upper and lower dentition

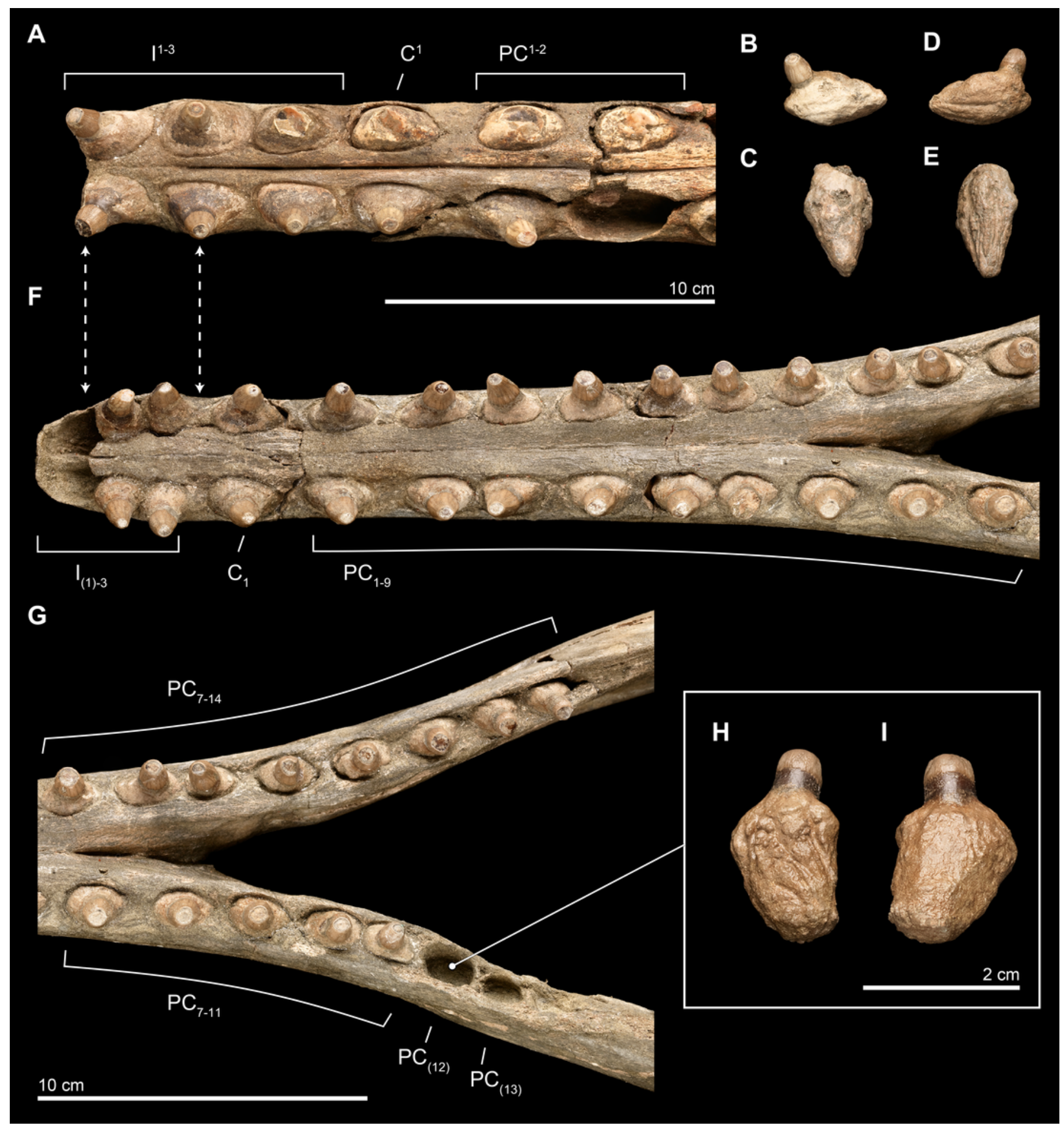




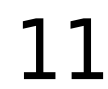

Scapula in lateral, medial, and distal views

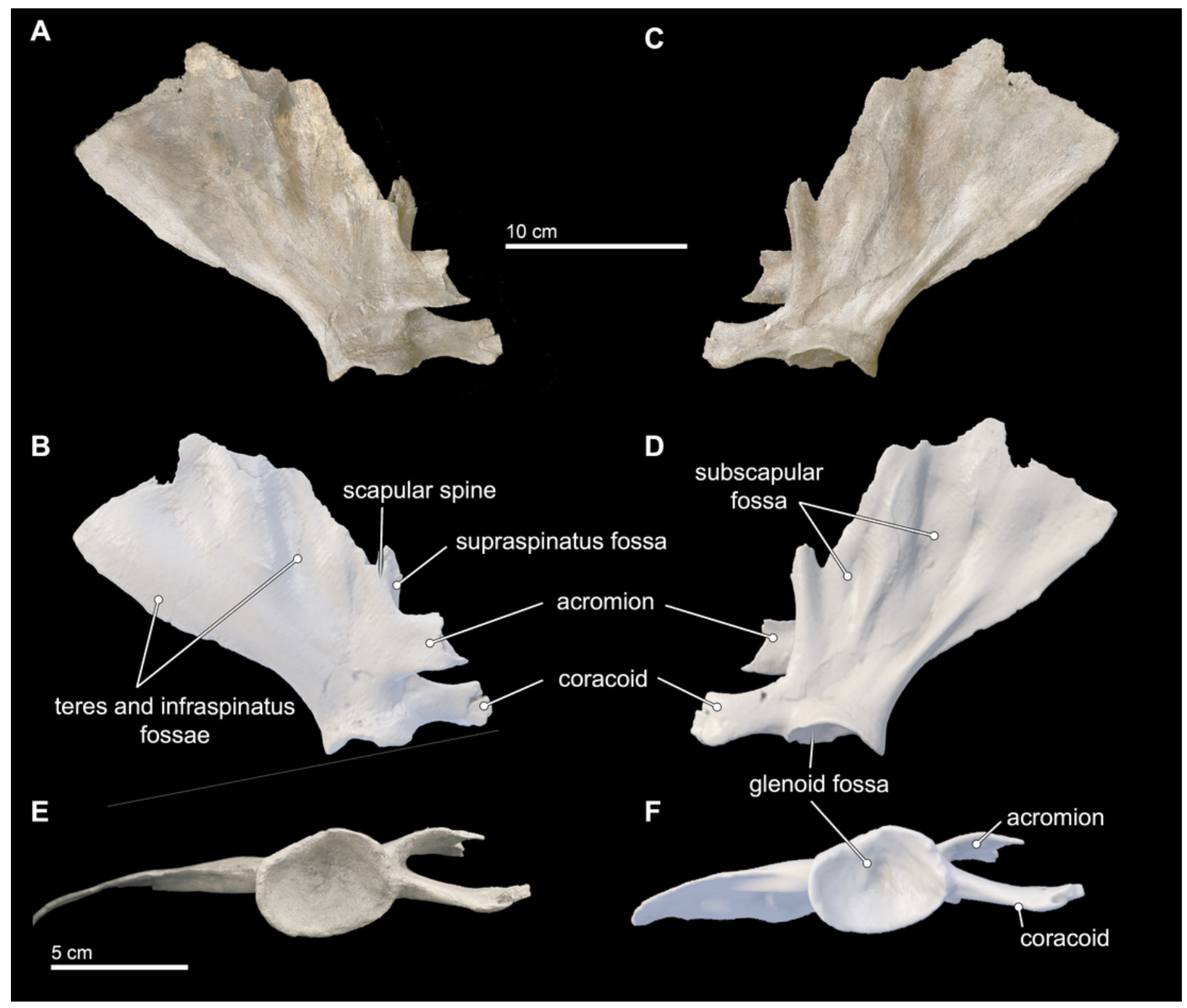


12

Carpal elements

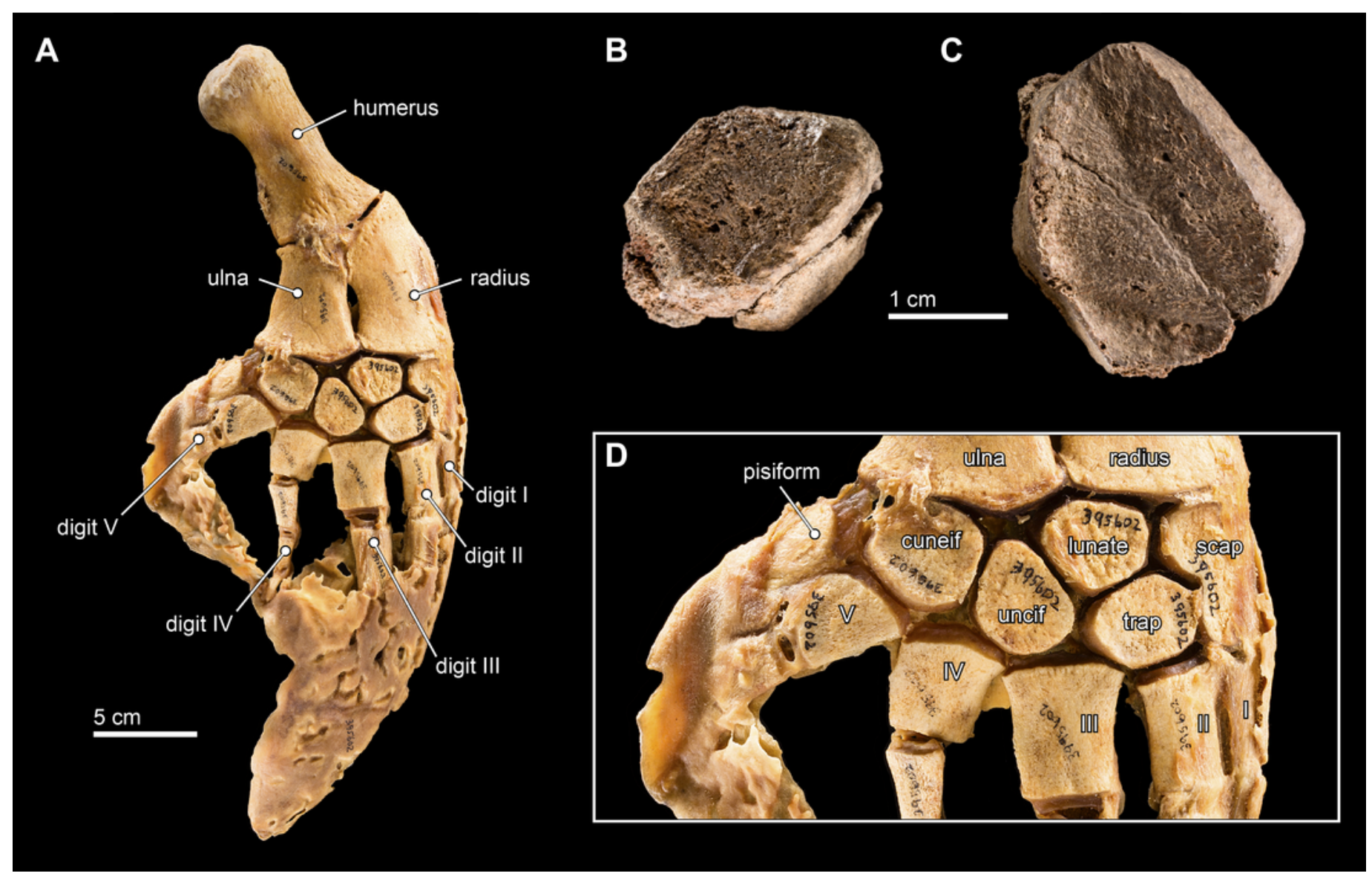


13

Consensus phylogenetic tree 


\section{PeerJ Reviewing Manuscript}

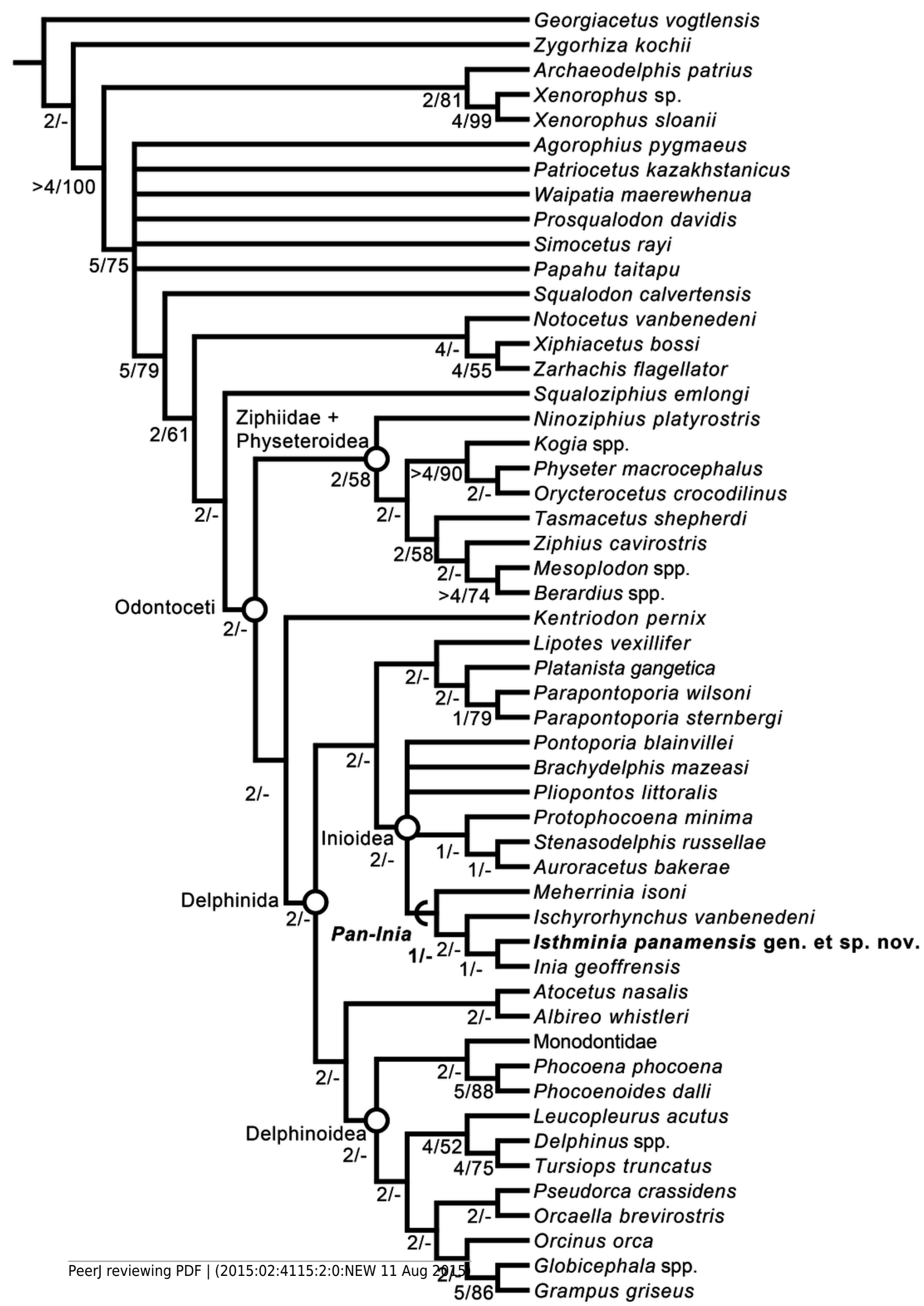


14

Reconstruction of Isthminia

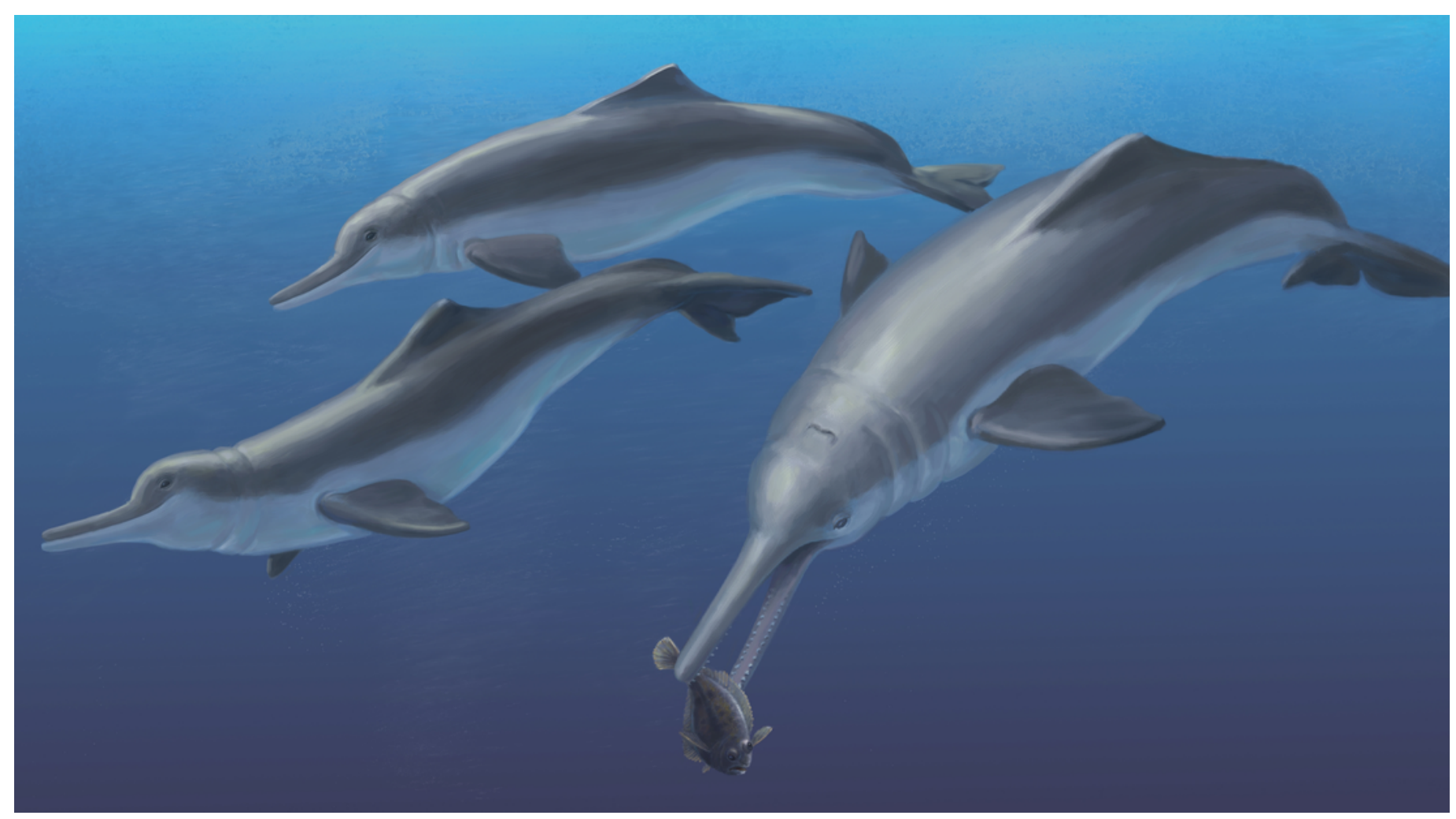


Stratigraphically calibrated phylogenetic tree of Inioidea

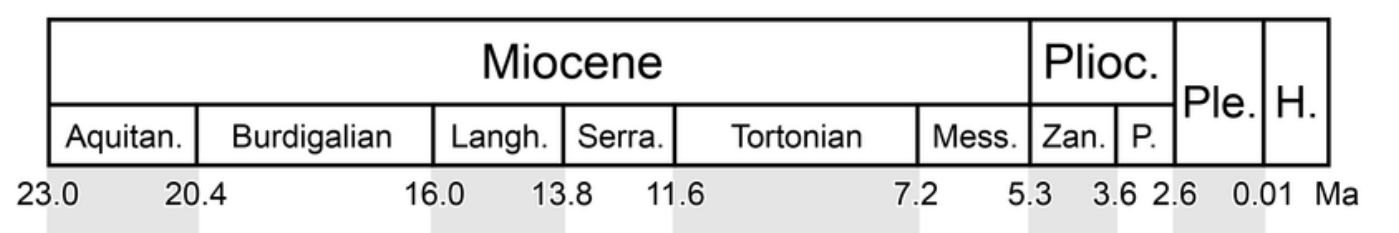

$\triangle$ Mixed

Freshwater

Marine

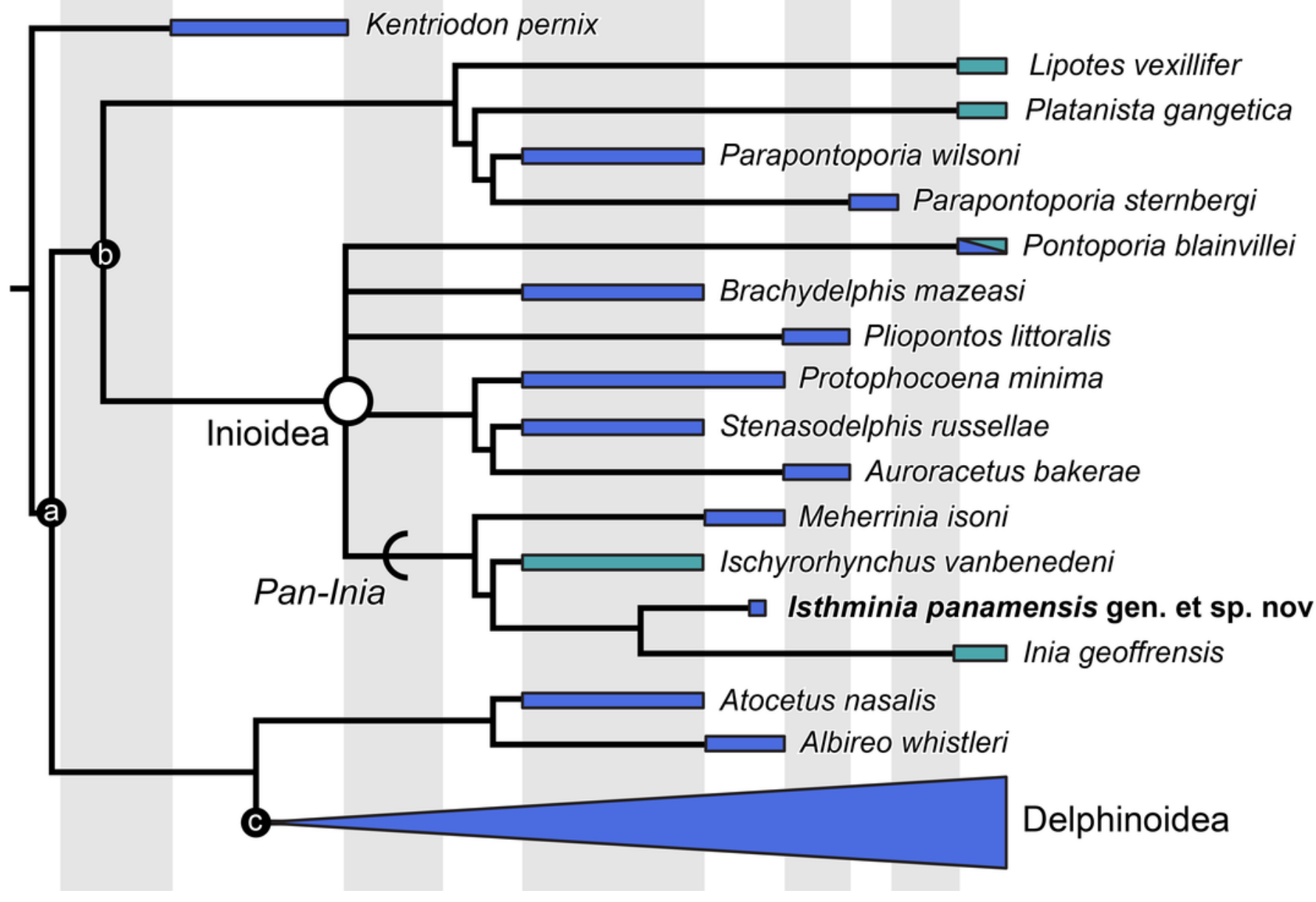

